KAPL-4825

UC- 904, Materials

(DOE/TIC-4500-R75)

\title{
Neutron Cross Sections for Uranium-235 (ENDF/B-VI Release 3)
}

\author{
Cecil Lubitz
}

\section{KAPL-4825}

Prepared for

The United States Department of Energy

Prepared by

The Knolls Atomic Power Lab, Inc.

PO Box 1072

Schenectady, NY 12303

Contract No. DE-AC12-76-SN00052 


\section{Disclạimer}

This report was prepared as an account of work sponsored by an agency of the United States Government. Neither the Unites States Government nor any agency thereof, nor any of their employees, makes any warranty, expressed or implied, or assumes any legal liability or responsibility for the accuracy, completeness, or usefulness of any information, apparatus, product, or process disclosed, or represents that its use would not infringe privately owned rights. Reference herein to any specific commercial product, process, or service by trade name, trademark, manufacturer, or otherwise, does not necessarily constitute or imply its endorsement, recommendation, or favoring by the United States Government or any agency thereof. The views and opinions of authors expressed herein do not necessarily state or reflect those of the United States. 


\section{DISCLAIMER}

Portions of this document may be illegible in electronic image products. Images are produced from the best available original document. 


\section{DISCLAIMER}

This report was prepared as an account of work sponsored by an agency of the United States Government. Neither the United States Government nor any agency thereof, nor any of their employees, makes any warranty, express or implied, or assumes any legal liability or responsibility for the accuracy, completeness, or usefulness of any information, apparatus, product, or process disclosed, or represents that its use would not infringe privately owned rights. Reference herein to any specific commercial product, process, or service by trade name, trademark, manufacturer, or otherwise does not necessarily constitute or imply its endorsement, recommendation, or favoring by the United States Government or any agency thereof. The views and opinions of authors expressed herein do not necessarily state or reflect those of the United States Government or any agency thereof. 


\section{CONTENTS}

Page

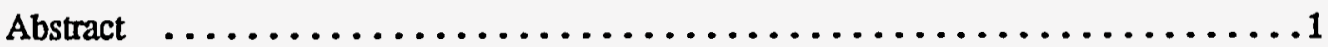

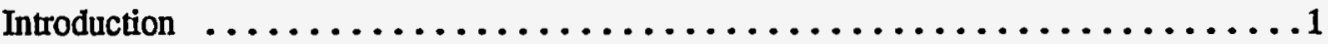

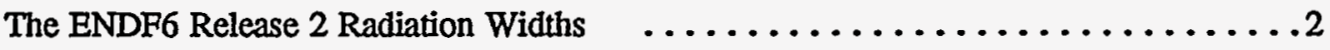

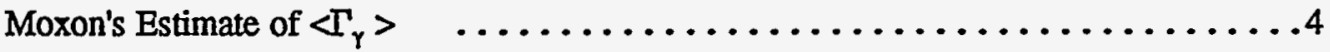

Initial Procedures for Epithermal Alpha $\ldots \ldots \ldots \ldots \ldots \ldots \ldots \ldots \ldots \ldots$

Final Procedure for Epithermal Alpha $\ldots \ldots \ldots \ldots \ldots \ldots \ldots \ldots \ldots \ldots \ldots \ldots \ldots \ldots \ldots$

Adjustment of $\mathrm{K} 1$ for the Thermal Region $\ldots \ldots \ldots \ldots \ldots \ldots \ldots \ldots$

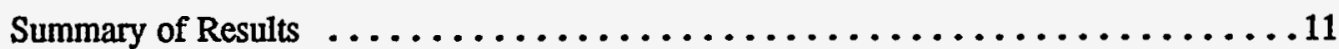

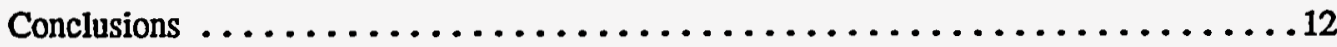

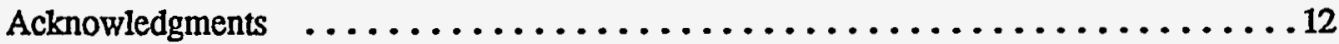

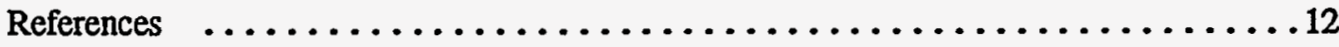

Appendices: Comparison of ENDF6 Release 3 with ENDF6 Release 2 and with Experiment Appendix A. Summary of Capture and Fission Bin Multipliers . . . . . . . . . . 14

Appendix B. Summary of Resonance-Width Multipliers $\ldots \ldots \ldots \ldots \ldots \ldots \ldots$

Appendix C. Fission and Capture Integrals and Averages $\ldots \ldots \ldots \ldots \ldots \ldots$

Appendix D. Comparison of Bin-Averaged Alpha: Experiment, Release 2, Release $3 \ldots 18$

Appendix E. Resonance Integrals and Epithermal Alpha from $0.5 \mathrm{eV}$ to Various Upper

Limits .................................19

Appendix F. Comparison with the Fort-Salvatores Result $\ldots \ldots \ldots \ldots \ldots \ldots$

Appendix G. Czirr Self-Indication Experiment $\ldots \ldots \ldots \ldots \ldots \ldots \ldots \ldots \ldots$

Appendix H. Region-Averaged Radiation Widths in Release $3 . \ldots \ldots \ldots \ldots \ldots .25$

Figures:

1. Oak Ridge and Rocky Flats Solution Tank Experiments. Comparison of

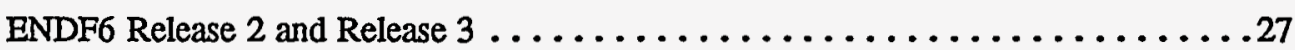

2. - 28. Graphical Comparison Between ENDF6 Release 2 and Release $3 \ldots \ldots \ldots 28$ 


\section{FIGURES}

Figure

Page

1 Oak Ridge and Rocky Flats Solution Tank Experiments, Comparison of ENDF6 Release 2 and Release 3

Figures 2 through 28: Graphical Comparison Bețeen ENDF̧6 Release 2 and Release 3

ENDF6 Release 3 vs. Release 2 (Total Cross Section) . . . . . . . . . . . . . . 29

ENDF6 Release 3 vs. Release 2 (Capture Cross Section) $\ldots \ldots \ldots \ldots \ldots \ldots \ldots \ldots \ldots \ldots \ldots \ldots \ldots$

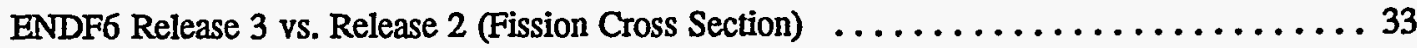

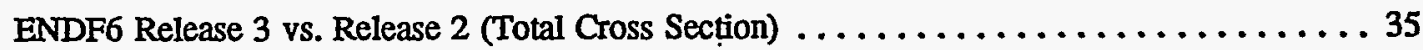

ENDF6 Release 3 vs. Release 2 (Capture Cross Section) $\ldots \ldots \ldots \ldots \ldots \ldots \ldots \ldots \ldots$

ENDF6 Release 3 vs. Release 2 (Fission Cross Section) $\ldots \ldots \ldots \ldots \ldots \ldots \ldots \ldots \ldots \ldots$

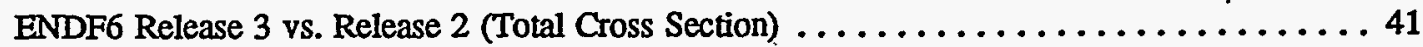

ENDF6 Release 3 vs. Release 2 (Capture Cross Section) . . . . . . . . . . . . 43

10 ENDF6 Release 3 vs. Release 2 (Fission Cross Section) $\ldots \ldots \ldots \ldots \ldots \ldots \ldots \ldots \ldots$

11 ENDF6 Release 3 vs. Release 2 (Total Cross Section) $\ldots \ldots \ldots \ldots \ldots \ldots \ldots \ldots \ldots \ldots$

12 ENDF6 Release 3 vs. Release 2 (Capture Cross Section) . . . . . . . . . . . . . . 49

13 ENDF6 Release 3 vs. Release 2 (Fission Cross Section) $\ldots \ldots \ldots \ldots \ldots \ldots \ldots \ldots \ldots$

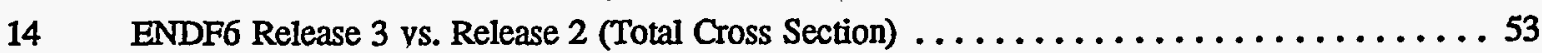

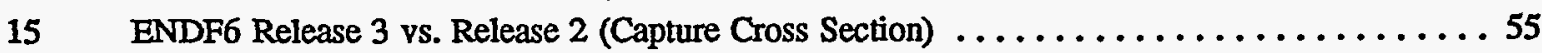

16. ENDF6 Release 3 vs. Release 2 (Fission Cross Section) $\ldots \ldots \ldots \ldots \ldots \ldots \ldots \ldots \ldots$

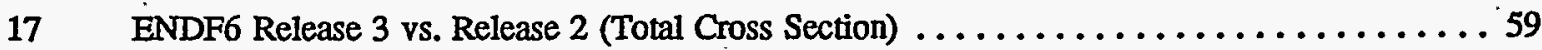

18 ENDF6 Release 3 vs. Release 2 (Capture Cross Section) $\ldots \ldots \ldots \ldots \ldots \ldots \ldots \ldots \ldots$

19 ENDF6 Release 3 vs. Release 2 (Fission Cross Section) $\ldots \ldots \ldots \ldots \ldots \ldots \ldots \ldots \ldots$

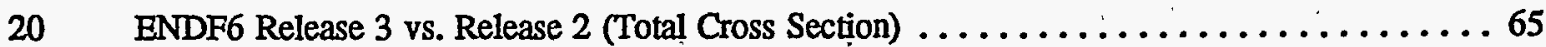

21 ENDF6 Release 3 vs. Release 2 (Capture Cross Section) $\ldots \ldots \ldots \ldots \ldots \ldots \ldots \ldots \ldots$

22 ENDF6 Release 3 vs. Release 2 (Fission Cross Section) $\ldots \ldots \ldots \ldots \ldots \ldots \ldots \ldots$

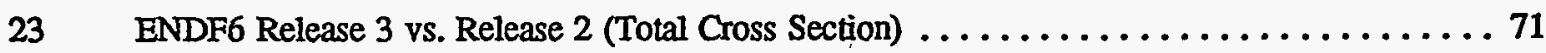

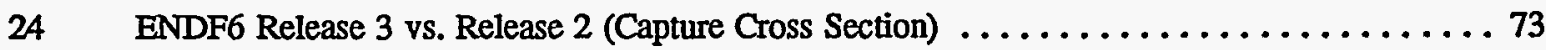

25 ENDF6 Release 3 vs. Release 2 (Fission Cross Section) $\ldots \ldots \ldots \ldots \ldots \ldots \ldots \ldots \ldots$

26 ENDF6 Release 3 vs. Release 2 (Total Cross Section) $\ldots \ldots \ldots \ldots \ldots \ldots \ldots \ldots \ldots \ldots$

27 ENDF6 Release 3 vs. Release 2 (Capture Cross Section) $\ldots \ldots \ldots \ldots \ldots \ldots \ldots \ldots \ldots$

28 ENDF6 Release 3 vs. Release 2 (Fission Cross Section) $\ldots \ldots \ldots \ldots \ldots \ldots \ldots \ldots$

KAPL-4825 iv 
The resonance parameters in ENDF6 (Release 2) U235 were adjusted to make the average capture and fission cross sections below $900 \mathrm{eV}$ agree with selected differential capture and fission measurements. The measurements chosen were the higher of the credible capture measurements and the lower of the fission results, yielding a higher epithermal alpha. In addition, the $2200 \mathrm{~m} / \mathrm{s}$ cross sections were adjusted to obtain agreement with the integral value of $\mathrm{K} 1$. As a result, criticality calculations for thermal benchmarks, and agreement with a variety . of integral parameters, are improved.

\section{INTRODUCTION}

The ENDF6 evaluation of U235 combined an extensive Reich-Moore multilevel analysis of the resonance region with a re-fitting of the high-energy cross sections (References $1,2,3$ and 4). The resolved resonance region was carried to $2250 \mathrm{eV}$, and although the structure above about $150-200 \mathrm{eV}$ is not as well-resolved as that below, it is believed that for calculating self-shielding effects, these data are probably better than any other.

However, it was observed by the evaluators (Reference 1), and by the Cross Section Evaluation Working Group (CSEWG) Thermal Reactor Data Testing Subcommittee (J. Hardy, Jr., and others (Reference 5)), that the evaluation reflected a discrepancy between differential and integral measurements of the capture resonance integral, and through it the capture-to-fission ratio, $\alpha$, defined as the ratio of the capture integral to the fission integral. Mughabghab (Reference 6 ) quotes a value of $I_{\gamma}=144 \pm 6$ barns, which together with a fission integral $I_{f}=275 \pm 5$ barns gives an epithermal $\alpha=.523 \pm .024$. Integral measurements (References 7 and 8 ) give alphas around $.50-.51$, and U235 data sets based on such values behave acceptably in thermal reactor calculations.

In contrast, ENDF6 Release 2 (material number 9228) gives $\mathrm{I}_{\gamma}=133.5, \mathrm{I}_{\mathrm{r}}=279.1, \alpha=0.478$. These values were obtained from the NJOY (Reference 9) modules RECONR and BROADR, with a tolerance of $0.1 \%$ at $293^{\circ}$ Kelvin, integrating the pointwise cross sections with $1 / E$-weighting from $0.5 \mathrm{eV}$ to $20 \mathrm{MeV}$. The capture integral is insensitive to the upper cutoff, being essentially converged by $1 \mathrm{MeV}$, but the fission cross section increases at high energy and the 1/E-integral does not converge, making it necessary to quote the upper cutoff when comparing numbers. This caveat aside, it is clear that there is a differential-integral discrepancy in the capture integral, since Release 2 represents a careful fit to a selection of high-quality differential data. The low value of the Release 2 capture integral makes itself felt in calculations of the Oak Ridge aqueous assemblies, and other thermal benchmarks, as an upward trend of calculated criticality level (eigenvalue) versus leakage, traceable to too-little capture in the U235. Figure 1 illustrates this point with eigenvalues calculated using Monte Carlo with pointwise cross sections, similar to results which have been found at other laboratories. (These results were kindly provided by JP Weinman.) 
In this paper, we will argue that the Release 2 radiation widths below $500 \mathrm{eV}$, and as a result, the capture cross section, are underestimated. Increasing them by renormalizing the capture cross section to higher differential measurements results in a more credible set of microscopic cross sections that agree with the integral measurements. Specifically, the differential-integral discrepancy is reșolved by choosing the higher Perez/de Saussure capture measurements (Reference 10) over the de Saussure, et al. data (Reference 11), and by choosing fission values at the low end of the measured band, a mix of values from the National Institute of Science and Technology and Oak Ridge National Laboratory (References 12, 14, and 20). Favoring these "high-alpha" measurements results in an average $\Gamma_{\gamma}$ which is in agreement with the value independently arrived at by MC Moxon (Reference 13). As a practical matter, the major part of the adjustment comes from the Perez/deSaussure data; the "low" fission values are actually in quite good agreement with the "high" values.

The method used for achieving this renormalization is described below. Here we note that the extensive fitting effort which went into Release 2 is not lost in the adjustment. That is, the fits to the high-resolution total and fission cross sections are preserved because we start from the Release 2 resonance parameters, and make small adjustments to them to achieve the desired changes in resonance areas.

We adopted the following guidelines for the adjustments:

1. Increase the value of epithermal alpha, while minimizing the changes to ENDF6 Release 2, and staying within the uncertainties of the microscopic data. This adjustment was made to improve the calculation of high-leakage thermal aqueous assemblies.

2. Keep the high-energy cross sections in Release 2 unchanged. The first version of this adjustment carried it from $0.5 \mathrm{eV}$ to $50 \mathrm{keV}$, to improve the agreement with the $\alpha$-measurements of References 14,15 , and 16 . However, LW Weston felt that the ENDF6 evaluators had used high-energy accelerator data which they believed were more accurate, so the changes above $900 \mathrm{eV}$ were dropped. The region from 100 to $900 \mathrm{eV}$ has little influence on thermal reactors, but the adjustment was made in order to increase the capture-to-fission ratio for intermediate-spectrum reactors, without affecting the good results which Release 2 gives for fast assemblies.

3. Concentrate the changes on the capture cross section, since the fission and total are better known.

4. Increase the value of the thermal utilization parameter, $\mathrm{K} 1$, to agree with integral measurements, while minimizing the changes to the Release 2 thermal region. This was done to improve the calculation of low-leakage thermal aqueous assemblies.

\section{THE ENDF6 RELEASE 2 RADIATION WIDTHS}

Because of the large number of resonances treated ( -3500$)$, the ENDF6 analysis was broken into 11 regions, each of which was treated separately by the fitting code SAMMY (Reference 17). The following table shows the average $\Gamma_{\gamma}$ in each of these regions. These averages exclude the extra resonances which are outside of each region, but which are used to minimize "end-effects", because those same resonances are included in the interior 
of the adjacent regions, with slightly different values.

TABLE 1. AVERAGE RADIATION WIDTHS IN ENDF6 RELEASE 2, BY RESONANCE REGION

\begin{tabular}{|c|c|c|c|c|c|}
\hline $\begin{array}{c}\text { Region } \\
\text { Number }\end{array}$ & $\begin{array}{c}\text { LOWER } \\
\text { ENERGY } \\
(\mathrm{eV})\end{array}$ & $\begin{array}{c}\text { UPPER } \\
\text { ENERGY } \\
(\mathrm{eV})\end{array}$ & $\begin{array}{c}\mathrm{J}=3 \\
(\mathrm{meV})\end{array}$ & $\begin{array}{c}\mathrm{J}=4 \\
(\mathrm{meV})\end{array}$ & $\begin{array}{c}\text { BOTH } \\
\text { SPINS } \\
(\mathrm{meV})\end{array}$ \\
\hline 1 & -100 & 4 & 37 & 35.6 & 36.3 \\
\hline 2 & 4 & 110 & 34.8 & 34.8 & 34.8 \\
\hline 3 & 110 & 300 & 35.0 & 35.0 & 35.0 \\
\hline 4 & 300 & 500 & 35.0 & 35.0 & 35.0 \\
\hline 5 & 500 & 750 & 43.6 & 43.4 & 43.5 \\
\hline 6 & 750 & 1000 & 40.8 & 44.7 & 43.0 \\
\hline 7 & 1000 & 1250 & 43.6 & 46.2 & 45.0 \\
\hline 8 & 1250 & 1500 & 38.6 & 38.9 & 38.7 \\
\hline 9 & 1500 & 1750 & 38.6 & 38.6 & 38.6 \\
\hline 10 & 1750 & 2000 & 38.2 & 38.4 & 38.3 \\
\hline 11 & 2000 & 2250 & 34.1 & 33.8 & 33.9 \\
\hline $1-11$ & -100 & 2250 & 38.2 & 38.6 & 38.4 \\
\hline $1-2$ & -100 & 110 & 35.0 & 34.8 & 34.9 \\
\hline-2 & 0.5 & 110 & 34.9 & 34.9 & 34.9 \\
\hline & & & & & \\
\hline
\end{tabular}

The overall average is $38.4 \mathrm{meV}$, the result of averaging the $35 \mathrm{meV}$ values below $500 \mathrm{eV}$ with the larger values above 500 , but of course the capture integral is dominated by the former. Calculations showed that replacing the radiation widths in every region with the overall-average of $38.4 \mathrm{meV}$ gave a capture integral much closer to Mughabghab's integral value. It is generally believed that radiation widths in a nucleus as heavy as U235 will not fluctuate very much, and although it is difficult to quantify that statement, the jump from $35 \mathrm{meV}$ to approximately 44 which occurs at the $500 \mathrm{eV}$ cutpoint seems unphysical. LW Weston pointed out that above $100 \mathrm{eV}$ or so the observed "resonance" structure is really clumps of two or more resonances, so that the discontinuity may reflect a fitting artifact, rather than any real change in width. In any event, it was this discontinuity which suggested replacing the widths by the overall average, with the result that a possible solution to the low capture resonance integral problem was suggested.

While investigating this point, we noticed that Mughabghab (Reference 6) gives $\left\langle\Gamma_{\gamma}\right\rangle=35 \pm 2 \mathrm{meV}$, thus suggest- 
ing that the low Release 2 values were correct. However, inspection of his individual-resonance $\Gamma_{Y}$ values shows that they are all greater than 35, a seeming contradiction. Mughabghab's explanation is that he believes he chose the $35 \mathrm{meV}$ value to keep the calculated capture integral from going even higher than the 144 barns he recommended, and that he used it for those resonances which had not been measured. Unfortunately, the records on this were lost in the National Nuclear Data Center cutback. However, he agrees that the average value of $\Gamma_{Y}$ could easily be around $38 \mathrm{meV}$.

The ENDF6 fitting procedure relied prịncipally on total and fission cross section measurements, because they are more accurate than capture, although the results were compared to capture data as a check. LW Weston has suggested that errors in fission measurements tend to overestimate $\sigma_{\mathrm{f}}$. If this is true, then the radiation widths, which are implicitly determined by total-minus-fission, will tend to be underestimated. The evaluators made use of the deSaussure, et al. data (References 11 and 18), which are lower than that of Perez/de Saussure, et al. (Reference 10). It has been suggested that the former data were over-corrected for background, and assuming this to be true "explains" why the comparisons did not indicate any difficulty. A barrier to the direct use of capture data in the fitting process was the fact that SAMMY (Reference 17) had no multiple- scattering correction for capture yields at the time the fitting was done, while REFIT (Reference 19), which did, had no Reich-Moore fission capability. (Both codes were subsequently modified to add these capabilities.)

\section{MOXON'S ESTIMATE OF $\left\langle\Gamma_{\gamma}\right\rangle$}

In support of the present work, MC Moxon (Reference 13) used his REFIT code to examine a dozen or so resonances in $\mathrm{U} 235$ below $20 \mathrm{eV}$, using data he had measured in connection with the "drooping-eta" problem. Since REFTT did not have a multilevel fission capability, he selected resonances in which the fission was either small, or exhibited weak channel-interference effects. His estimate for $\left\langle\Gamma_{\gamma}\right\rangle$ was $38.2 \mathrm{meV}$, close to the overall average from Release 2, and significantly higher than the $35 \mathrm{meV}$ average below $500 \mathrm{eV}$. From earlier calculations it was known that simply replacing the Release 2 values with this average would raise $\alpha$ close to 0.50 . However, Moxon suggested that, in addition, each fission width be compensated for the changed radiation width, so that the total widths would remain unchanged. His argument was that $\Gamma$ was determined by the transmission data and was probably well-known. Since the transmission also determines the neutron widths, we kept them unchanged also. An attractive feature of this method was that a general increase in $\sigma_{\gamma}$ is accompanied by a corresponding decrease in $\sigma_{f}$, with an enhanced effect on $\alpha$.

In the same study, Moxon looked at the possibility that some small, mainly capture resonances might somehow have been missed in earlier measirements, but decided against that possibility. He also noted that his data gave slightly lower fission valleys than Release 2 , and that "trading" valley-fission for valley-capture was of the right magnitude to explain the alpha discrepancy. To use this last observation would have required re-fitting the data, which was not done. However, it is significant that the adjustment procedure which was used produced a similar 
effect and resulted in an average $\Gamma_{\gamma}$ that agrees with Moxon's estimate.

\section{INITIAL PROCEDURES FOR EPITHERMAL ALPHA}

It is generally believed that radiation widths in a heavy nucleus like U235 have a $\chi^{2}$-distribution with a large number of degrees of freedom, and should not fluctuate much from level to level. In view of the difficulty of measuring and fitting the individual widths, it can be argued that large fluctuations in $\Gamma_{\gamma}$ are artifacts of the fitting procedure, and that a more accurate representation of the true cross section can be obtained by constraining the widths to a single average value. It is common to see evaluations in which all the unmeasured widths have been given such a value, and this practice is generally accepted as accurate. Such arguments suggest that the Release 2 evaluation, which exhibits large fluctuations, could be improved by introducing this constraint. In Reference 1, the authors emphasize that above about $100 \mathrm{eV}$, the fitted parameters lose their significance as genuine "one-level" widths, and should simply be viewed as an accurate way to parameterize the measured structure for self-shielding purposes. This argument, which is reasonable, implies that average-value-replacement may not work above $100 \mathrm{eV}$ and, as we will discuss below, this turns out to be the case.

In our initial attempt to raise the epithermal-alpha value, all 3500 resonances in the Release 2 evaluation, extending up to $2250 \mathrm{eV}$, were adjusted as described above. The radiation widths were replaced by Moxon's 38.2 $\mathrm{meV}$, and each fission width was changed by an equal and opposite amount. The ratio of the two partial fission widths was kept unchanged. In order to keep the thermal cross sections from changing, the 9 resonances between $-100 \mathrm{eV}$ and $.5 \mathrm{eV}$ were treated differently. Their $\Gamma_{\gamma}$ 's and $\Gamma_{\mathrm{f}}$ 's were multiplied by iteratively-determined factors which preserved the $2200 \mathrm{~m} / \mathrm{s}$ values and (implicitly) the shape of the cross sections in the thermal region. Small additive background cross sections were added to File 3 (the ENDF "file" containing the backgrounds), in order to improve agreement with various capture, fission, and alpha bin-averages which have been measured and which played a role in the Release 2 analysis (References 10,11, 12, 14, 15, 16, 18, and 20). Each iteration was performed by manually changing the values in a computer code which read in the unperturbed Release 2 file, re-wrote the resonance parameters, and created an adjusted ENDF6-formatted file. NJOY was then used to convert the adjusted file to pointwise cross sections, from which the various quantities were calculated. The use of a Cray YMP made this procedure feasible.

The final file was slightly modified by switching from Moxon's $38.2 \mathrm{meV}$ estimate to 38.8 , in order to reduce the size of some of the File 3 background corrections, after which it was sent to Oak Ridge for review, kindly supplied by JA Harvey, LW Weston, and RQ Wright. They pointed out, in a private communication, that the algorithm resulted in rather large changes to the fission cross section whenever the change in $\Gamma_{\gamma}$ was large. Several resonances with small fission widths had large changes which resulted in serious differences between the adjusted shapes and experiment. Also, above $100 \mathrm{eV}$ the new deck exhibited widespread differences with measured fission cross sections on a detailed basis, although the bin-averages were reasonable. LW Weston, in 
particular, emphasized that above $100 \mathrm{eV}$ the ENDF6 analysis had fit the total and fission very carefully, but that the resonances could not be regarded as genuine resolved resonances. They were more likely clumps of two or three, or more, so that the procedure of replacing $\Gamma_{\gamma}$ by $\left\langle\Gamma_{\gamma}\right\rangle$ and then compensating with $\delta \Gamma_{f}$ was not physically reasonable. He suggested simply not changing the fission above $500 \mathrm{eV}$, and this recommendation was adopted. However, we used $900 \mathrm{eV}$, in order to accommodate the need for higher alpha in RQ Wright's intermediate-spectrum benchmarks.

The above objections were well-taken, and implied that the algorithm described above put too much emphasis on preserving the total cross section and too little on the fission, which was actually of comparable quality. In response to these suggestions, we generated a second-pass adjustment based on the same general principles of $\Gamma_{\gamma}$-replacement and $\Gamma_{r}$-compensation. However, we introduced various constraints on the size of the allowed change to any particular fission width. For example, small fission widths were not allowed to change at all, and we simply accepted the resultant change in the total width. In addition, we insisted on exact compensation between $\Gamma_{y}$ and $\Gamma_{f}$ only for the largest fission resonances, and relaxed the requirement as the fission area got smaller. This algorithm cured the most obvious problems with the first one, but still required File 3 background additions in order to match the desired bin-averages.

\section{FINAL PROCEDURE FOR EPITHERMAL ALPHA}

From the above results, it was clear that constraining the neutron widths to their original ENDF6 values was too restrictive, because they determined the total area under the resonances. Whenever matching the bin-averages required unequal changes to the capture and fission, and especially when they went in the same direction, fixing $\Gamma_{n}$ prevented the adjustments. This suggested the idea that we should somehow relax the constraints on $\Gamma_{n}$ which were imposed by the transmission data, accepting the minimum changes to the Release 2 parameters which would still allow the necessary changes in the capture cross section.

Since the transmission data are connected to the Doppler-broadened peak height and width of each resonance, we looked for a way to change the resonance parameters while preserving these shape-quantities as much as possible, given that the resonance areas had to change. This led to the following "resonance-adjustment" procedure:

1. The energy range from 0 to $900 \mathrm{eV}$ was divided into 12 bins, corresponding to intervals over which average capture, fission, and alpha measurements have been reported. They are listed in Appendix A.

2. The average fission, capture, and alpha from Release 2 were calculated over these bins and their ratios to the experimental values were determined. In this way. we determined multiplicative factors, $Q_{y}$ and $Q_{f}$, for capture and fission in each bin. The factors chosen were designed to make the adjusted averages agree with the lower end of the measured range of fission values and the higher end of the capture. These capture and fission bin- 
multipliers are listed in Appendix A. Note that this is not an integral adjustment. Although integral experiments initially pointed to the discrepant area, the adjustment was made entirely on the basis of differential measurements. In addition, the procedure results in a set of resonance parameters which require no background corrections in File 3.

3. Each set of resonance parameters was adjusted individually, up to $900 \mathrm{eV}$, in such a way that each resonance increased (or decreased) its capture area by the capture bin-multiplier for the bin in which the resonance was located. At the same time, its fission area changed according to the value of the fission bin-multiplier. The changes were expressed as two equations, relating the adjusted parameters to their original Release 2 values, which are indicated by a superscript zero in the following equations. In the spirit of the Single-Level BreitWigner (SLBW) formalism on which the area estimates were based, we neglected the influence of Dopplerbroadening on the areas:

$$
\begin{aligned}
& \Gamma_{\mathrm{n}} \Gamma_{\gamma} / \Gamma=Q_{Y} \Gamma_{\mathrm{n}}^{0} \Gamma_{Y}^{0} / \Gamma^{0} \\
& \Gamma_{\mathrm{n}} \Gamma_{\mathrm{I}} / \Gamma=\mathrm{Q}_{\mathrm{Y}} \Gamma_{\mathrm{n}}{ }^{0} \Gamma_{\mathrm{f}}^{0} \Gamma^{0}
\end{aligned}
$$

$Q_{\gamma}$ and $Q_{f}$ are the bin multipliers and the width ratios are (proportional to) SLBW estimates of the areas. Since there are three variables $\left(\Gamma=\Gamma_{n}+\Gamma_{\gamma}+\Gamma_{\partial}\right)$, one more equation is needed. We chose to require that the Doppler-broadened peak height of the adjusted total cross section should differ from the unadjusted value by the same percentage as the Doppler-broadened peak height of the adjusted fission cross section differed from its unadjusted value. If $\sigma$ denotes a Doppler-broadened peak height, this "statement of equality" is

$$
\left(1 \sigma_{t}-\sigma_{t}^{0}\right) / \sigma_{t}^{0}=\left(1 \sigma_{f}-\sigma_{f}^{0}\right) / \sigma_{f}^{0}
$$

The absolute-value signs were inserted to allow both the total and the fission peak heights to deviate from their Release 2 values in either direction, but in practice they always went oppositely. The reason for this is that equation (3) is deceptively simple. It appears to say merely that we want equal weight to be given to preserving the fission and total peak heights in the Release 2 analysis. This is reasonable, and in fact it does just that. However, it also enforces the equality as a mathematical identity. At one point in the analysis, we tried introducing a weight $\mathrm{W}$ into equation (3). The intent was to make the total peak height deviation smaller, percentage-wise, than the fission whenever the fission area was small, in the belief that such resonances would have lower statistical accuracy in the fission measurements. Equation (3) produced unreasonable values of the widths under these circumstances, apparently because it enforced an exact diminution of the total ratio on the lefthand-side of equation (3) relative to the r.h.s. A better way to reach the intended goal would be to solve the three equations subject to fuzzy-logic rules, something like "Keep the total peak height as close as possible to its 
Release 2 value, and do the same for the fission, but if the fission area is small, let it deviate more than the total, while keeping the parameters close to the unperturbed values". With such an approach, one could introduce additional constraints on the parameters, perhaps minimizing the fluctuations in $\Gamma_{\gamma}$, or requiring them to have values close to integer multiples of the "real" value when fitting clumps of resonances. However, the best course for a future re-evaluation would be to renormalize the de Saussure, et al. data to Perez/de Saussure; renormalize the fission data to the "low end" values; and adopt the modified $2200 \mathrm{~m} / \mathrm{s}$ values described below. That would allow one to re-fit the same data that were originally fit, but would guarantee the higher alpha and $\mathrm{K} 1$ arrived at in this work.

The three equations were solved by introducing the Voight profile to represent $\sigma,(\theta=\Gamma / \Delta)$

$$
\Psi(\theta, 0)=\frac{\sqrt{\pi}}{2} \theta \exp \left(\frac{\theta^{2}}{4}\right) \operatorname{erfc}\left(\frac{\theta}{2}\right)
$$

This made the equations transcendental via the error function, necessitating the use of an iterative technique to solve them. In practice, it was found necessary to also iterate on the Q-values a few times, in order to get the bin-averages to their desired values. Presumably this was because the equations are SLBW, but the formalism used is Reich-Moore, so that the area and peak-height estimates calculated from the former were not quite in agreement with the actual quantities calculated from the latter. In Appendix A we compare the bin-multipliers that were read into the code with the actual ratios which resulted. In most cases they agree very closely, but some are a few percent different. In view of the spread in the measured values of the various bin-averages, it was not considered necessary to iterate further.

\section{ADJUSTMENT OF KI FOR THE THERMAL REGION}

When the above work was completed, Monte Carlo calculations of the Oak Ridge and other thermal assemblies, carried out by JP Weinman at KAPL, AC Kahler at Bettis, and RQ Wright at ORNL, showed that the increased epithermal alpha satisfactorily remedied the leakage-bias seen with Release 2. However, Kahler pointed out that the low-leakage results were still systematically low with respect to experiment, and that this had been linked by the CSEWG Thermal Benchmark Testing Subcommittee to the value of the thermal reactivity parameter K1 in Release 2.

$\mathrm{K} 1$ is defined in terms of thermal nu-bar $(v)$, and $2 / \sqrt{ } \pi$ times the Maxwellian-averaged fission, capture, and absorption cross sections, $\mathrm{F}, \mathrm{C}$, and $\mathrm{A}=\mathrm{F}+\mathrm{C}$ :

$$
\mathrm{K} 1=\bar{v} \mathrm{~F}-\mathrm{A}=(\bar{v}-1) \mathrm{F}-\mathrm{C} .
$$


In terms of Westcott g-factors and $2200 \mathrm{~m} / \mathrm{s}$ cross sections, $\mathrm{F}=\mathrm{g}_{\mathrm{f}} \sigma_{\mathrm{f}}, \mathrm{C}=\mathrm{g}_{\gamma} \sigma_{\gamma}$, etc.

For Release 2, we calculated $\mathrm{K} 1=721.2$, using a Maxwellian temperature of $.0253 \mathrm{eV}$, while the Benchmark Sub-

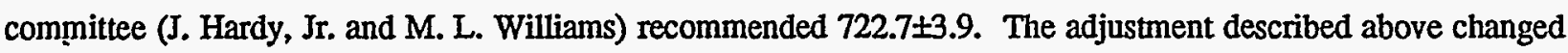
this to 720.7 , a slight reduction from Release 2 , because even though we constrained the $2200 \mathrm{~m} / \mathrm{s}$ values to be the same as Release 2 , the increased epithermal $\alpha$ slightly affected the shapes in the thermal region.

We decided to match the recommended "integral" $\mathrm{K} 1$ by adopting new $2200 \mathrm{~m} / \mathrm{s}$ cross sections, while preserving the "drooping-eta" shapes in Release 2. However, instead of starting from the Release 2 values, we started from the values recommended by the CSEWG Standards Subcommittee under AD Carlson, quoted in Reference 2:

$$
\begin{aligned}
& \sigma_{y}=98.96 \pm 0.74(0.75 \%) \\
& \sigma_{f}=584.25 \pm 1.11(0.19 \%) \\
& \bar{v}=2.4320 \pm 0.0036(0.15 \%)
\end{aligned}
$$

The principle that we applied was that we would increase $\bar{v}$ and $\sigma_{f}$ and decrease $\sigma_{\gamma}$, constraining the changes so that each one would be the same fraction of its quoted uncertainty. This would produce the desired increase in K1 while minimizing the adjustment to the Standards cross sections. The method that we used was to apply a factor slightly greater than 1.0 to the fission widths for the 9 resonances below $0.5 \mathrm{eV}$ in Release 2, while applying a factor slightly less than 1.0 to their capture widths, using the same factors for all 9 resonances. In this way we hoped to preserve the shapes of the thermal-region cross sections as much as possible. For each choice of factors, a new ENDF-formatted file was produced, and NJOY was re-run to make the pointwise cross sections. From these, the new $2200 \mathrm{~m} / \mathrm{s}$ cross sections and Maxwellian averages were calculated, and from them and the desired value of $K 1$ (722.7), the required value of $\bar{v}$ was obtained. The changes in $\bar{v}, \sigma_{f}$ and $\sigma_{\gamma}$ were then examined to see how much they had changed from the Standards values. This was repeated iteratively until the desired equal-percentage changes were obtained. This occurred when the changes were 0.5 of a standard deviation for each quantity, as follows:

\begin{tabular}{|c|c|c|c|c|c|}
\hline \multicolumn{7}{|c|}{$2200 \mathrm{~m} / \mathrm{s}$ values } \\
\hline Quantity & New value & Standards & New - Standards & Release 2 & New - Release 2 \\
\hline$\sigma_{\gamma}$ & 98.59 & 98.96 & $-0.37(-0.37 \%)$ & 98.83 & $-0.24(-0.24 \%)$ \\
\hline$\sigma_{f}$ & 584.81 & 584.25 & $+0.56(+0.10 \%)$ & 584.39 & $+0.42(+0.07 \%)$ \\
\hline $\bar{v}$ & 2.4338 & 2.4320 & $+0.0018(+0.07 \%)$ & 2.4320 & $+.0018(+0.07 \%)$ \\
\hline
\end{tabular}

The g-factors are essentially unchanged from Release 2 , indicating that the thermal adjustment did not affect the 
drooping-eta shape. In the following table, [G] denotes the value quoted in the Gatlinburg paper (Reference 25); the differences are due to a change in interpolation procedures. (The statement made during the oral presentation of that paper, that the g-factors unexpectedly moved closer to the Standards values, proved subsequently to be sensitive to the choice of interpolation scheme used in calculating the factors.)

\begin{tabular}{|c|l|l|l|}
\hline \multicolumn{3}{|c|}{ g-factors and Maxwellian averages (times $2 / \sqrt{ } \pi$ ) } \\
\hline Quantity & $\begin{array}{c}\text { This } \\
\text { evaluation }\end{array}$ & $\begin{array}{c}\text { Standards } \\
\text { Subcommittee }\end{array}$ & Release 2 \\
\hline $\mathrm{g}_{\mathrm{\gamma}}$ & 0.9897 & $0.9902 \pm .0008$ & 0.9895 \\
& $0.9895[\mathrm{G}]$ & & $0.9938[\mathrm{G}]$ \\
\hline $\mathrm{g}_{\mathrm{f}}$ & 0.9786 & $0.9771 \pm .0008$ & 0.9786 \\
& $0.9784[\mathrm{G}]$ & & $0.9770[\mathrm{G}]$ \\
\hline $\mathrm{K} 1$ & 723.0 & 719.5 (implied) & 721.2 \\
& $722.8[\mathrm{G}]$ & & $721.0[\mathrm{G}]$ \\
\hline $\mathrm{C}$ & 97.57 & 98.00 (implied) & 97.79 \\
& $97.56[\mathrm{G}]$ & & $97.77[\mathrm{G}]$ \\
\hline F & 572.28 & 570.87 (implied) & 571.90 \\
& $572.17[\mathrm{G}]$ & & $571.77[\mathrm{G}]$ \\
\hline
\end{tabular}

The result of this change on the thermal assembly eigenvalues can be seen in Figure 1. The dotted curve represents a linear fit to the Release 2 eigenvalues, and exhibits a rise of about 0.0100 in $\mathrm{k}$ over the range of leakages in the figure. The zero-leakage intercept is about 0.9967 . The epithermal-alpha adjustment, without the K1-adjustment, reduces the rise from 0.0100 to about 0.0030 over the same range of leakage, but has little effect on the zero-leakage intercept. The Release-3 linear fit combines the epithermal-alpha adjustment and the $\mathrm{K} 1$ adjustment, as shown by the solid line in Figure 1. The K1-adjustment does not affect the slope, but increases the zero-leakage intercept from 0.9967 to about 0.9987 , an improvement of about 0.0020 in the low-leakage average eigenvalue. This is consistent with the "predicted" change deduced from the K1-values, since their ratio is $723.0 / 721.2=1.0025$. The remaining difference between the zero-leakage intercept and 1.0000, and the remaining slope, may be due to small errors in the ENDF6 capture cross sections for hydrogen and U238, and to the oxygen angular distributions, as well as any' remaining errors in the U235.

\section{SUMMARY OF RESULTS}

After applying the above procedures, and matching the desired bin-averages, the resulting cross sections agreed 
with the following data: (The agreement is spelled out in detail in the Appendices.)

1. Integral estimates of the capture and fission resonance integrals and their ratio $\alpha$.

2. Fission averages at the low end of the experimental "band".

3. Capture averages at the high end.

4. Fast benchmark critical eigenvalues, unchanged from Release 2.

5. Oak Ridge and Rocky-Flats aqueous solution critical assemblies. The changes relative to Release 2 are a reduction in eigenvalue at the high-leakage end, and an increase at the low end. These are due to the increases in epithermal alpha and $\mathrm{K} 1$, respectively. This improvement carries over to thermal assemblies in general.

6. MC Moxon's estimate of $\left\langle\Gamma_{Y}\right\rangle$.

7. The Release 2 total and fission microscopic cross sections, to within a few percent.

8. The Release 2 capture cross sections, except that an effective renormalization took place, to make the averages agree with the higher Perez/de Saussure data.

9. Agreement with the Czirr experiment is about the same as Release 2, quite good over most regions.

10. The $2200 \mathrm{~m} / \mathrm{s}$ values for fission and capture, and for thermal nu-bar are each one-half of a standard deviation different from the ENDF Standards, while the "drooping-eta " shape remains intact. Release 2 was closer to the Standards on the thermal values, but paid a penalty in low thermal eigenvalues.

11. We were not able to accommodate the Fort-Salvatores finding (Reference 21) that Release 2 capture is $12 \%$ low in the range 450-2000 eV (see Appendix F).

12. RQ Wright (Reference 24) reported some improvement in intermediate-spectrum core results.

13. A. Jonsson (Reference 24) reported improvement in fuel cycle calculations .

It should be noted that it was not necessary to violate any microscopic constraints to arrive at these results. It was only necessary to bias the choice of fission microscopic data toward the low side and capture to the high side. In one instance, namely the $0.5-10.0 \mathrm{eV}$ bin, there was no "high-side" capture, because the de Saussure, et al. capture integral, $231.6 \mathrm{~b}-\mathrm{eV}$, was the only measurement. In this case, a "pseudo-Perez/de Saussure" ratio was calculated from the neighboring bins. From 10.0-50.0 eV Perez/de Saussure measured 1252, while de Saussure, et al. measured 1178 , for a ratio of 1.063 . From $50.0-100.0 \mathrm{eV}$ the values were $747 / 721=1.036$, so that an interval-weighted average is 1.048 . This was applied to the 231.6 value to get 242.7. Release 3 actually used 242.2 as its value, $4.6 \%$ above de Saussure, et al. Another measurement of this important number would be desirable.

A gratifying feature, which was not anticipated, is the agreement with Moxon's $38.2 \mathrm{meV}$ average radiation width, since the method used to generate Release 3, namely "renormalization" to the Perez/de Saussure and "low-fission" bin averages, made no use of an average $\Gamma_{\gamma}$. Also, in the region up to $10 \mathrm{eV}$, there is an increase in valley capture, accompanied by a decrease in fission, as suggested by Moxon's data, although we have not made a quantitative comparison. 


\section{CONCLUSIONS}

Based on the points enumerated in the preceding section, it appears that ENDF6 Release 3 preserves the many good features of Release 2, while remedying the low alpha and $\mathrm{K} 1$ problems in a physically reasonable way. Benchmark testing shows that it does a good job on thermal and fast reactors. The principal finding with respect to alpha is that the Perez/deSaussure capture normalization is preferred to that of deSaussure, et al. The adjustment of $\mathrm{K} 1$ was done in such a way as to minimize the changes to the CSEWG Standards Subcommittee recommended values. While a reasonable approach, it is by no means unique, since there is a strong correlation between the cross section shapes, which we did not adjust, and the $2200 \mathrm{~m} / \mathrm{s}$ cross sections which we did. We believe Release 3 to be a credible representation of the thermal region, which removes the aqueous-assembly leakage bias seen with Release 2 .

\section{ACKNOWLEDGEMENTS}

LW Weston, RQ Wright, and JA Harvey (ORNL) provided invaluable advice and feedback at all stages of this work. MC Moxon (Harwell) provided guidance and suggestions in the early phases, took on the challenge of determining the "real value" of $\left\langle\Gamma_{\gamma}\right\rangle$, and suggested the fission-width-compensation procedure. AC Kahler (Bettis) checked the calculations at all stages of the work, helped in debugging some problems with NJOY, and made other useful suggestions along the way, including the desirability of increasing K1. R. E. MacFarlane (LANL) helped us with the intricacies of the NJOY system, whose Reich-Moore processing capabilities were used throughout this work. An essential element in guiding the analysis were the numerous Monte Carlo benchmark calculations made by JP Weinman (KAPL), which were a bottom-line indicator of how well the different preliminary and intermediate versions, of which there were many, performed on the Oak Ridge and Rocky Flats aqueous assemblies. Similar work was done by AC Kahler and RQ Wright, contributing in an essential way to the successful conclusion of this work.

\section{REFERENCES}

(1) G deSaussure, LC Leal, RB Perez, NM Larson, and MS Moore, "A New Resonance Region Evaluation of Neutron Cross Sections for 235U", NSE 103 (1989) 109.

(2) AD Carlson, W Poenitz, et al., "ENDF6 Neutron Cross Section Measurement Standards", NISTIR 5177 (ENDF-351)1990.

(3) LC Leal, G de Saussure, and RB Perez, "An R-Matrix Analysis of the 235U Neutron-Induced Cross Sections up to $500 \mathrm{eV}$ ", NSE 109 (1991) 1.

(4) LC Leal, "Resonance Analysis and Evaluation of the 235U Neutron Induced Cross Sections", ORNL TM-11547, June 1990.

(5) Ad Hoc ORELA Meeting, February 1988; CSEWG Minutes 1988. 
(6) SF Mughabghab, Neutron Cross Sections, Volume 1, Academic Press, 1984.

(7) HM Eiland, F Feiner, et al., NSE 44 (1971) 180.

(8) DE Conway and SB Gunst, NSE 29 (1967) 1.

(9) RSIC Code Package PSR-171, "NJOY", Oak Ridge National Laboratory, 1992.

(10) R. B. Perez, G deSaussure, et al., NSE $\underline{52}$ (1973) 46.

(11) G. de Saussure, et al., ORNL/TM-1804, (1967).

(12) RC Schrack, Internat'l Conf. on Nuclear Data for Science and Technology, Mito, Japan, 1988.

(13) MC Moxon, "Comments on the ENDF/B-VI Evaluation for U235 in the Neutron Energy Region from 1 to 20 eV", ORNL/TM-12304 (ENDF-355) , February 1993.

(14) R Gwin, et al., NSE $\underline{59}$ (1976) 79.

(15) GV Muradyan, et al,, Proc. Int'. Conf. on Neutron Cross Sections for Technology, Knoxville, 1979, p. 488.

(16) VA Konshin, et al., Proc. of the III All-Union Conference on Neutron Physics, Kiev, 1976.

(17) N.M. Larson, ORNL/TM-9179/R2, 1989.

(18) G de Saussure, LW Weston, R Gwin, RW Hockenbury, "Measurement of the 235U Neutron Capture-to-Fission Ratio, $\alpha$, for Incident Energies from $3.25 \mathrm{eV}$ to $1.8 \mathrm{keV}^{\prime \prime}$, NSE $\underline{23}$ (1965) 45.

(19) M.C. Moxon, "REFIT Users' Manual", April 1991.

(20) LW Weston and JH Todd, NSE 111 (1992) 415.

(21) E Fort and M Salvatores, preprint distributed at the May 1993 CSEWG meeting.

(22) LW Weston, PG Young, and WP Poenitz, File 1 comments in ENDF/B-VI Release 2 material number 9228, November 1989.

(23) JB Czirr, NSE 70 (1979) 307.

(24) Minutes of the October 1995 CSEWG Meeting, Brookhaven National Laboratory.

(25) CR Lubitz, "A Modification to ENDF6 U235 to Increase Epithermal Alpha and K1", International Conf. on Nuclear Data for Science and Technology, Gatlinburg, Tennessee, May 1994, p. 646. 
All Release 3 numbers quoted in this report were calculated on a 64-bit Cray YMP in single-precision, from an ENDF6-formatted input file. We used NJOY 91.38 , with a reconstruction tolerance of $0.1 \%$ in both RECONR and BROADR, at a temperature of $293 \mathrm{~K}$. The values labelled "Release $2^{\text {" }}$ were obtained the same way from the Release 2 ENDF6 tape. The numbers differ a little from the values in References 1 and 22, which differ somewhat between themselves. A source of differences in what are referred to as "ENDF6" by different authors, besides the reconstruction tolerances and reconstruction procedures, is that the original ENDF6 Release 0 deck differs from Release $1 / 2$, and the $500-\mathrm{eV}$ version of the original deck (References 3 and 4 ) is also slightly different. The most apparent difference among these evaluations is the "drooping-eta" shape in Releases 1 and 2, but there is also a small difference in the average radiation width over $0-500 \mathrm{eV}(36 \mathrm{meV}$ in the $500-\mathrm{eV}$-deck, 35 $\mathrm{meV}$ in Release $1 / 2$ ).

Release 3 was run with the following input cards to the NJOY modules RECONR and BROADR:

RECONR: $\quad 00106.01$ 1.0E-4 / ERR TEMPR NDIGITS ERRMAX ERRINT .

BROADR: $\quad .001$ 1.E6 .01 1.0E-4 / ERRTHN THNMAX ERRMAX ERRINT

For later versions, in particular our production version, we tightened ERRINT to $1 . e-6$ in both modules. This is a further source of some small differences in quoted numbers.

APPENDIX A. SUMMARY OF CAPTURE AND FISSION BIN MULTIPLIERS.

As explained in the accompanying report, Release 3 was arrived at by adjusting ENDF6 Release 2 to a variety of bin-averaged fission, capture, and $\alpha$ values. Each resonance had its parameters individually adjusted so that its capture area and its fission area changed by these factors, depending on which bin the resonance was in. As a result, Release 3 is a straight resonance deck, as was Release 2, requiring no background cross sections in the resonance region. The following table shows the values of the bin-multipliers for capture that were read into the computer program, and the actual ratio of Release 3 capture to original Release 2 which resulted. There are small differences between these numbers which are not of practical significance, and which are presumably due to the SLBW nature of the adjustment equations. These bins are different from the resonance regions into which the ENDF6 evaluation was divided. In bins $1-4$, the multipliers were obtained from the Perez/de Saussure capture data; above that from Gwin's alpha measurements. The numbers in the following table, and in later tables, were computer-generated, so that the number of significant figures does not have any physical significance, or in any way indicate an implied accuracy. 
CAPTURE BIN-MULTIPLIERS

\begin{tabular}{|c|c|c|c|c|}
\hline BIN NO. & E-LOW & E-HIGH & READ IN & ACTUAL \\
\hline 1 & $5.00 \mathrm{E}-1$ & $1.00 \mathrm{E}+1$ & 1.06345 & 1.0607 \\
\hline 2 & $1.00 \mathrm{E}+1$ & $5.00 \mathrm{E}+1$ & 1.06004 & 1.0588 \\
\hline 3 & $5.00 \mathrm{E}+1$ & $1.00 \mathrm{E}+2$ & 1.08728 & 1.0806 \\
\hline 4 & $1.00 \mathrm{E}+2$ & $1.10 \mathrm{E}+2$ & 1.15277 & 1.1423 \\
\hline 5 & $1.10 \mathrm{E}+2$ & $2.00 \mathrm{E}+2$ & 1.28717 & 1.2852 \\
\hline 6 & $2.00 \mathrm{E}+2$ & $3.00 \mathrm{E}+2$ & 1.32191 & 1.3041 \\
\hline 7 & $3.00 \mathrm{E}+2$ & $4.00 \mathrm{E}+2$ & 1.26095 & 1.2598 \\
\hline 8 & $4.00 \mathrm{E}+2$ & $5.00 \mathrm{E}+2$ & 1.30978 & 1.3261 \\
\hline 9 & $5.00 \mathrm{E}+2$ & $6.00 \mathrm{E}+2$ & 0.84096 & 0.8451 \\
\hline 10 & $6.00 \mathrm{E}+2$ & $7.00 \mathrm{E}+2$ & 1.18604 & 1.1808 \\
\hline 11 & $7.00 \mathrm{E}+2$ & $8.00 \mathrm{E}+2$ & 1.11765 & 1.1156 \\
\hline 12 & $8.00 \mathrm{E}+2$ & $9.00 \mathrm{E}+2$ & 1.07448 & 1.0759 \\
\hline
\end{tabular}

The following table shows the values of the bin-multipliers for fission that were read in, and the actual ratio of Release 3 fission to original Release 2 which resulted. As might be expected, the differences are somewhat larger than for the capture values, since multilevel effects are more severe. It should be noted, however, that the changes to Release 2 fission are very small, exceeding a percent and a half in only two bins. The reason for this is that the fission measurements are all in good agreement, so that the "low value", which we chose, is quite close to the higher ones.

FISSION BIN-MULTIPLIERS

\begin{tabular}{|c|c|c|c|c|}
\hline BIN NO. & E-LOW & E-HIGH & READ IN & ACTUAI \\
\hline 1 & 0.5 & 10 & 0.9817 & 0.9853 \\
\hline 2 & 10 & 50 & 0.99519 & 0.9943 \\
\hline 3 & 50 & 100 & 1.00108 & 0.9985 \\
\hline 4 & 100 & 110 & 0.97444 & 0.9763 \\
\hline 5 & 110 & 200 & 1.00865 & 1.0055 \\
\hline
\end{tabular}


FISSION BIN-MULTIPLIERS (Continued)

\begin{tabular}{|c|c|c|c|c|}
\hline BIN NO. & E-LOW & E-HIGH & READ IN & ACTUAL \\
\hline 6 & 200 & 300 & 1.0141 & 1.0021 \\
\hline 7 & 300 & 400 & 0.99168 & 0.9862 \\
\hline 8 & 400 & 500 & 1.04089 & 1.0163 \\
\hline 9 & 500 & 600 & 0.9786 & 0.9891 \\
\hline 10 & 600 & 700 & 0.99046 & 0.9852 \\
\hline 11 & 700 & 800 & 1.00284 & 0.992 \\
\hline 12 & 800 & 900 & 0.9399 & 0.9613 \\
\hline
\end{tabular}

APPENDIX B. SUMMARY OF RESONANCE-WIDTH MULTIPLIERS.

In the first part of this work, it was our intention to increase epithermal alpha while leaving the Release 22200 $\mathrm{m} / \mathrm{s}$ fission and capture cross sections unchanged. Accordingly, the resonance-adjustment procedure which we employed was applied only to the resonances above $.5 \mathrm{eV}$. Nevertheless, this epithermal adjustment induced small changes in the thermal parameters. To get back to the original Release 2 values we adjusted the widths of the first 9 resonances, all below $0.5 \mathrm{eV}$, by multiplying their widths by the following factors, determined by trial and error:

$\Gamma_{\gamma}$ was multiplied by $0.99883 ; \Gamma_{\mathrm{f}}$ was multiplied by 0.99987 .

These are very close to unity, verifying that the changes to the ENDF6 thermal region were insignificant, and this was borne out by actual comparisons of the cross sections.

In the subsequent K1-adjustment phase, we again adjusted the widths of the first 9 resonances, using the iterative technique described above. The resulting factors were 0.99599 (capture) and 1.00113 (fission), so that the final ratios of these widths to Release 2 were 0.99482 (capture) and 1.00100 (fission).

APPENDIX C. FISSION AND CAPTURE INTEGRALS AND AVERAGES.

In the following table, the values labelled "Weston92" are from Reference 20. The values "Weston+" are preliminary values used in Release 2. 
BIN-AVERAGED FISSION (barns)

\begin{tabular}{|c|c|c|c|c|c|c|}
\hline Energy bin, $\mathrm{eV}$ & Schrack & Gwint & Wagemanst & Weston+ & Release 2 & Release 3 \\
\hline $.0206-.06239$ & 459.0 & 460.9 & 460.9 & - & 459.7 & 459.7 \\
\hline $7.8-11.0$ & 74.8 & 77.3 & 76.9 & - & 76.9 & 75.6 \\
\hline $0.5-10$ & 41.8 & 42.7 & 42.7 & $-\cdots$ & 42.6 & 41.9 \\
\hline $10-50$ & 44.90 & 45.96 & 45.95 & - & 45.18 & 44.91 \\
\hline $50-100$ & 31.72 & 32.64 & 32.95 & 32.04 & 31.76 & 31.72 \\
\hline $100-110$ & 18.6 & 18.3 & 19.1 & 18.8 & 18.8 & 18.33 \\
\hline $100-200$ & 20.91 & 20.48 & 20.97 & 21.14 & 20.66 & 20.72 \\
\hline \hline Energy bin, eV & Schrack & Weston+ & Weston92 & Standards & Release 2 & Release 3 \\
\hline $200-300$ & 20.05 & 20.15 & 20.43 & 20.67 & 20.05 & 20.09 \\
\hline $300-400$ & 13.21 & 12.86 & 12.99 & 13.14 & 13.15 & 12.97 \\
\hline $400-500$ & 13.83 & 13.53 & 13.64 & 13.79 & 13.37 & 13.59 \\
\hline $500-600$ & 14.63 & 14.77 & 14.87 & 15.19 & 14.95 & 14.79 \\
\hline $600-700$ & 11.46 & 11.27 & 11.34 & 11.47 & 11.49 & 11.32 \\
\hline $700-800$ & 10.79 & 10.79 & 10.86 & 11.14 & 10.89 & 10.80 \\
\hline $800-900$ & 7.82 & 7.95 & 8.00 & 8.25 & 8.32 & 8.00 \\
\hline
\end{tabular}

In the following table, the Perez/de Saussure "guesstimate" over $0.5-10.0 \mathrm{eV}$ was obtained by averaging the ratios of Perez/de Saussure-to-de Saussure, et al. in the adjacent regions, as described on page 11. This number plays a major role in determining $I_{\gamma}$, and it would be desirable to remove some of the arbitrariness in the current procedure by additional measurements, as suggested by LW Weston.

In the other three bins, Release 3 is a straight adjustment of Release 2 to the Perez/de Saussure values. A significant number in the following table is the Release 2 average from 0.5 to $10.0 \mathrm{eV}, 228.3 \mathrm{barns}-\mathrm{eV}$. It is below the de Saussure value (231.6), which itself is believed to be too low. This region plays a crucial role in determining the resonance integral. 
BIN-AVERAGED CAPTURE INTEGRALS (barns-eV)

\begin{tabular}{|c|c|c|c|c|}
\hline Energy bin, eV & de Saussure, et al. & Perez/de Saussure & Release 2 & Release 3 \\
\hline $0.5-10$ & 231.6 & 246.1 & 228.3 & 242.2 \\
\hline $10-50$ & 1178 & 1252 & 1183 & 1252.2 \\
\hline $50-100$ & 721 & 747 & 691 & 746.9 \\
\hline $100-110$ & 158 & 176 & 154 & 175.8 \\
\hline
\end{tabular}

APPENDIX D. COMPARISON OF BIN-AVERAGED ALPHA: EXPERIMENT, RELEASE 2, RELEASE 3.

In the following table, the Release 3 values were obtained by first adjusting the bin-averaged fission to the previously-noted Schrack-Gwin-Wagemans-Weston values, favioring the lower end of the band. The capture was then adjusted to match the Gwin alpha-values up to $900 \mathrm{eV}$. This provides higher capture in the intermediate-spectrum region, per a suggestion by RQ Wright, but keeps the fast criticals in agreement with Release 2, which does a good job on GODIVA, etc. The references for Gwin, et al., Muradyan and Konshin are 14, 15, and 16 , respectively.

In one bin, from $500-600 \mathrm{eV}$, using the Gwin alpha produced a result lower than Release 2, opposite from all the other bins. The comparison with Fort and Salvatores' adjustment factor, in Appendix F, suggests that the higher value is better.

\begin{tabular}{|c|c|c|c|c|c|c|c|c|}
\hline \multirow{2}{*}{$\begin{array}{c}\text { EMIN } \\
\mathrm{eV}\end{array}$} & $\begin{array}{c}\text { EMAX } \\
\mathrm{eV}\end{array}$ & Gwin & Konshin & Muradyan & Release 2 & \multicolumn{3}{|c|}{ Release 3 } \\
\cline { 7 - 9 } & & & & & alpha & capture & fission \\
\hline 200 & 200 & 0.600 & 0.580 & 0.490 & 0.476 & 0.599 & 12.422 & 20.722 \\
\hline 300 & 300 & 0.450 & 0.434 & 0.378 & 0.345 & 0.450 & 9.032 & 20.090 \\
\hline 400 & 500 & 0.350 & 0.349 & 0.304 & 0.268 & 0.350 & 4.753 & 13.587 \\
\hline 500 & 600 & 0.290 & 0.294 & 0.272 & 0.339 & 0.290 & 4.284 & 14.791 \\
\hline 600 & 700 & 0.420 & 0.392 & 0.331 & 0.350 & 0.420 & 4.757 & 11.322 \\
\hline 700 & 800 & 0.450 & 0.417 & 0.363 & 0.400 & 0.450 & 4.859 & 10.805 \\
\hline 800 & 900 & 0.510 & 0.485 & 0.437 & 0.456 & 0.511 & 4.085 & 8.000 \\
\hline
\end{tabular}




\begin{tabular}{|l|l|l|l|l|l|}
\hline \multirow{2}{*}{ EMIN } & \multirow{2}{*}{ EMAX } & \multicolumn{2}{|c|}{ Capture } & \multicolumn{2}{c|}{ Fission } \\
\cline { 3 - 6 } & & Release 2 & Release 3 & Release 2 & Release 3 \\
\hline 100 & 200 & 9.836 & 12.422 & 20.663 & 20.722 \\
\hline 200 & 300 & 6.926 & 9.032 & 20.047 & 20.090 \\
\hline 300 & 400 & 5.352 & 6.742 & 13.150 & 12.969 \\
\hline 400 & 500 & 3.584 & 4.753 & 13.369 & 13.587 \\
\hline 500 & 600 & 5.070 & 4.284 & 14.955 & 14.791 \\
\hline 600 & 700 & 4.028 & 4.757 & 11.493 & 11.322 \\
\hline 700 & 800 & 4.356 & 4.859 & 10.892 & 10.805 \\
\hline 800 & 900 & 3.795 & 4.085 & 8.322 & 8.000 \\
\hline
\end{tabular}

APPENDIX E. RESONANCE INTEGRALS AND EPITHERMAL ALPHA FROM 0.5 EV TO VARIOUS UPPER LIMITS.

\begin{tabular}{|c|c|c|c|}
\hline Range (eV) & Capture & Fission & Ratio (alpha) \\
\hline $0.5-1 \mathrm{E}+6$ & 143.37 & 273.27 & 0.5246 \\
\hline $0.5-10 \mathrm{E}+6$ & 143.45 & 276.22 & 0.5193 \\
\hline $0.5-15 \mathrm{E}+6$ & 143.45 & 276.97 & 0.5179 \\
\hline $0.5-20 \mathrm{E}+6$ & 143.45 & 277.55 & 0.5169 \\
\hline
\end{tabular}

APPENDIX F. COMPARISON WITH THE FORT-SALVATORES RESULT.

In the Fort-Salvatores benchmark study, (Reference 21), they report that Release 2 capture is too low by $12 \%$ in the region from 450-2000 ev. This is consistent with other indications from harder-spectrum cores that Release 2 alpha is also too low above the region to which we confined our adjustment $(0-900 \mathrm{eV})$. However, our adjustment used only the Gwin, et al. alphas, and actually reduced Release 2 capture in the bin from 500-600 eV. As a result, the $450-2000 \mathrm{eV}$ average is above Release 2 only by $2.5 \%$ and therefore still in disagreement with the Fort and Salvatores estimate. In retrospect, it might have been better to use that result rather than the Gwin value. Using the Gwin alpha values above $900 \mathrm{eV}$, i.e., in $900-2000 \mathrm{eV}$, would raise Release 3 somewhat, but 
would still not match the F-S value.

AVERAGE CAPTURE OVER 450-2000 EV:

Release 2: $\quad 3.57$

Release 2+12\%: 4.00 (Fort and Salvatores "estimate")

Release 3: $\quad 3.66$

APPENDIX G. CZIRR SELF-INDICATION EXPERIMENT (Reference 23)

This experiment passes the neutron beam through a uranium "filter" and measures the fission rate in a second U235 detector. The shielded fission rate is calculated from

$$
R(x, G)=\frac{\int_{G} \sigma_{E}(E) \exp \left[-x \Sigma_{T}(E)\right] d E / E}{\int_{G} \sigma_{E}(E) d E / E}
$$

where

$$
\begin{aligned}
& G=\text { energy bin index (shown below) } \\
& \mathrm{X}=\text { uranium filter thickness } \\
& \sigma_{\mathrm{f}}={ }^{235} \mathrm{U} \text { fission cross section } \\
& \Sigma_{\mathrm{T}}=\text { uranium total macroscopic cross section }
\end{aligned}
$$

\section{SIX SAMPLE THICKNESSES, 11 ENERGY BINS}

The Release 2 evaluation does a good job of reproducing these numbers, in some instances remarkably good, and Release 3 does not change that agreement.

CASE 1. SAMPLE THICKNESS IS 0.504 GMS/CM**2 U.

REGION 1, SHIELDED=4.484E+1, UNSHIELDED=4.995E+1, RATIO=8.978E-1

REGION 2, SHIELDED=2.448E+1, UNSHIELDED=2.751E+1, RATIO=8.897E-1

REGION 3, SHIELDED=1.193E+1, UNSHIELDED=1.291E+1, RATIO=9.235E-1

REGION 4, SHIELDED=2.361E+1, UNSHIELDED=3.595E+1, RATIO=6.569E- 1

REGION 5, SHIELDED=2.534E+1, UNSHIELDED=3.782E+1, RATIO=6.700E-1

REGION 6, SHIELDED=2.562E+1, UNSHIELDED=3.225E+1, RATIO=7.946E-1

REGION 7, SHIELDED=2.290E+1, UNSHIELDED=2.659E +1 , RATIO=8.612E-1 
REGION 8, SHIELDED=1.436E+1, UNSHIELDED=1.578E+1, RATIO=9.105E-1 REGION 9, SHIELDED=1.179E+1, UNSHIELDED=1.266E+1, RATIO=9.311E-1 REGION 10, SHIELDED=8.190E+0, UNSHIELDED=8.590E+0, RATIO=9.535E-1 REGION 11, SHIELDED=5.277E+0, UNSHIELDED=5.473E+0, RATIO=9.641E-1

$\begin{array}{cllllc}\text { REGION } & \text { E-LOWER } & \text { E-UPPER } & \text { EXPT } & \text { CALC } & \text { (C-E) / E (PCT.) } \\ 1 & 4.64 \mathrm{E}-1 & 1.00 \mathrm{E}+0 & 0.880 & 0.898 & 2.0 \\ 2 & 1.00 \mathrm{E}+0 & 2.15 \mathrm{E}+0 & 0.898 & 0.890 & -0.9 \\ 3 & 2.15 \mathrm{E}+0 & 4.64 \mathrm{E}+0 & 0.924 & 0.923 & -0.1 \\ 4 & 4.64 \mathrm{E}+0 & 1.00 \mathrm{E}+1 & 0.631 & 0.657 & 4.1 \\ 5 & 1.00 \mathrm{E}+1 & 2.15 \mathrm{E}+1 & 0.640 & 0.670 & 4.7 \\ 6 & 2.15 \mathrm{E}+1 & 4.64 \mathrm{E}+1 & 0.793 & 0.795 & 0.2 \\ 7 & 4.64 \mathrm{E}+1 & 1.00 \mathrm{E}+2 & 0.865 & 0.861 & -0.4 \\ 8 & 1.00 \mathrm{E}+2 & 2.15 \mathrm{E}+2 & 0.898 & 0.911 & 1.4 \\ 9 & 2.15 \mathrm{E}+2 & 4.64 \mathrm{E}+2 & 0.941 & 0.931 & -1.1 \\ 10 & 4.64 \mathrm{E}+2 & 1.00 \mathrm{E}+3 & 0.939 & 0.953 & 1.5 \\ 11 & 1.00 \mathrm{E}+3 & 2.15 \mathrm{E}+3 & 0.938 & 0.964 & 2.8\end{array}$

CASE 2. SAMPLE THICKNESS IS 0.794 GMS/CM**2 U.

REGION 1, SHIELDED=4.215E+1, UNSHIELDED=4.995E+1, RATIO=8.438E-1 REGION 2, SHIELDED=2.292E+1, UNSHIELDED=2.751E+1, RATIO=8.330E-1 REGION 3, SHIELDED=1.141E+1, UNSHIELDED=1.291E+1, RATIO=8.833E-1 REGION 4, SHIELDED=1.964E+1, UNSHIELDED=3.595E+1, RATIO=5.462E-1 REGION 5, SHIELDED=2.161E+1, UNSHIELDED=3.782E+1, RATIO=5.714E-1 REGION 6, SHIELDED=2.283E+1, UNSHIELDED=3.225E+1, RATIO=7.081E-1 REGION 7, SHIELDED=2.112E+1, UNSHIELDED=2.659E+1, RATIO=7.946E-1 REGION 8, SHIELDED=1.363E+1, UNSHIELDED=1.578E+1, RATIO=8.641E-1 REGION 9, SHIELDED=1.132E+1, UNSHIELDED=1.266E+1, RATIO=8.944E-1 REGION 10, SHIELDED=7.970E+0, UNSHIELDED=8.590E+0, RATIO=9.279E-1 REGION 11, SHIELDED=5.167E+0, UNSHIELDED=5.473E+0, RATIO=9.441E-1

$\begin{array}{clllll}\text { REGION } & \text { E-LOWER } & \text { E-UPPER } & \text { EXPT } & \text { CALC } & \text { (C-E) / E (PCT.) } \\ 1 & 4.64 \mathrm{E}-1 & 1.00 \mathrm{E}+0 & 0.848 & 0.844 & -0.5 \\ 2 & 1.00 \mathrm{E}+0 & 2.15 \mathrm{E}+0 & 0.840 & 0.833 & -0.8 \\ 3 & 2.15 \mathrm{E}+0 & 4.64 \mathrm{E}+0 & 0.874 & 0.883 & 1.1 \\ 4 & 4.64 \mathrm{E}+0 & 1.00 \mathrm{E}+1 & 0.514 & 0.546 & 6.3 \\ 5 & 1.00 \mathrm{E}+1 & 2.15 \mathrm{E}+1 & 0.524 & 0.571 & 9.1 \\ 6 & 2.15 \mathrm{E}+1 & 4.64 \mathrm{E}+1 & 0.693 & 0.708 & 2.2 \\ 7 & 4.64 \mathrm{E}+1 & 1.00 \mathrm{E}+2 & 0.785 & 0.795 & 1.2 \\ 8 & 1.00 \mathrm{E}+2 & 2.15 \mathrm{E}+2 & 0.867 & 0.864 & -0.3 \\ 9 & 2.15 \mathrm{E}+2 & 4.64 \mathrm{E}+2 & 0.894 & 0.894 & 0.0 \\ 10 & 4.64 \mathrm{E}+2 & 1.00 \mathrm{E}+3 & 0.932 & 0.928 & -0.4 \\ 11 & 1.00 \mathrm{E}+3 & 2.15 \mathrm{E}+3 & 0.919 & 0.944 & 2.7\end{array}$

CASE 3. SAMPLE THICKNESS IS 1.968 GMS/CM**2 U.

REGION 1, SHIELDED=3.283E+1, UNSHIELDED=4.995E+1, RATIO=6.572E-1 
REGION 2, SHIELDED=1.774E+1, UNSHIELDED=2.751E+1, RATIO=6.448E-1 REGION 3, SHIELDED=9.613E+0, UNSHIELDED=1.291E+1, RATIO=7.443E-1 REGION 4, SHIELDED=1.193E+1, UNSHIELDED=3.595E+1, RATIO=3.318E-1 REGION 5, SHIELDED=1.452E +1, UNSHIELDED=3.782E +1, RATTO=3.840E-1 REGION 6, SHIELDED=1.565E +1, UNSHIELDED=3.225E+1, RATIO=4.852E-1 REGION 7, SHIELDED=1.574E+1, UNSHIELDED=2.659E +1, RATIO=5.921E-1 REGION 8, SHIELDED=1.115E+1, UNSHIELDED=1.578E+1, RATIO=7.068E-1 REGION 9, SHIELDED=9.679E+0, UNSHIELDED=1.266E +1, RATIO=7.647E-1 REGION 10, SHIELDED=7.148E+0, UNSHIELDED=8.590E+0, RATIO=8.321E-1 REGION 11, SHIELDED=4.749E+0, UNSHIELDED $=5.473 \mathrm{E}+0$, RATIO=8.678E-1

$\begin{array}{clllll}\text { REGION } & \text { E-LOWER } & \text { E-UPPER } & \text { EXPT } & \text { CALC } & \text { (C-E) / E (PCT.) } \\ 1 & 4.64 \mathrm{E}-1 & 1.00 \mathrm{E}+0 & 0.662 & 0.657 & -0.7 \\ 2 & 1.00 \mathrm{E}+0 & 2.15 \mathrm{E}+0 & 0.672 & 0.645 & -4.0 \\ 3 & 2.15 \mathrm{E}+0 & 4.64 \mathrm{E}+0 & 0.719 . & 0.744 & 3.5 \\ 4 & 4.64 \mathrm{E}+0 & 1.00 \mathrm{E}+1 & 0.297 & 0.332 & 11.7 \\ 5 & 1.00 \mathrm{E}+1 & 2.15 \mathrm{E}+1 & 0.352 & 0.384 & 9.1 \\ 6 & 2.15 \mathrm{E}+1 & 4.64 \mathrm{E}+1 & 0.477 & 0.485 & 1.7 \\ 7 & 4.64 \mathrm{E}+1 & 1.00 \mathrm{E}+2 & 0.605 & 0.592 & -2.1 \\ 8 & 1.00 \mathrm{E}+2 & 2.15 \mathrm{E}+2 & 0.719 & 0.707 & -1.7 \\ 9 & 2.15 \mathrm{E}+2 & 4.64 \mathrm{E}+2 & 0.780 & 0.765 & -2.0 \\ 10 & 4.64 \mathrm{E}+2 & 1.00 \mathrm{E}+3 & 0.841 & 0.832 & -1.1 \\ 11 & 1.00 \mathrm{E}+3 & 2.15 \mathrm{E}+3 & 0.847 & 0.868 & 2.5\end{array}$

CASE 4. SAMPLE THICKNESS IS 3.852 GMS/CM**2 U.

REGION 1, SHIELDED=2.204E+1, UNSHIELDED=4.995E+1, RATIO=4.412E-1 REGION 2, SHIELDED=1.218E+1, UNSHIELDED=2.751E+1, RATTO=4.428E-1 REGION 3, SHIELDED=7.496E+0, UNSHIELIDED=1.291E+1, RATIO=5.804E-1 REGION 4, SHIELDED=7.426E +0, UNSHIELDED=3.595E+1, RATIO=2.066E-1 REGION 5, SHIELDED=9.862E +0, UNSHIELDED=3.782E+1, RATIO=2.608E-1 REGION 6, SHIELDED=1.007E+1, UNSHIELDED=3.225E+1, RATIO=3.124E-1 REGION 7, SHIELDED=1.059E+1, UNSHIELDED=2.659E+1, RATTO=3.983E-1 REGION 8, SHIELDED=8.309E+0, UNSHIELDED=1.578E +1 , RATIO=5.267E-1 REGION 9, SHIELDED $=7.654 \mathrm{E}+0$, UNSHIELDED $=1.266 \mathrm{E}+1, \mathrm{RATIO}=6.047 \mathrm{E}-1$ REGION 10, SHIELDED=6.027E+0, UNSHIELDED=8.590E+0, RATIO=7.017E-1 REGION 11, SHIELDED=4.155E+0, UNSHIELDED $=5.473 \mathrm{E}+0$, RATIO=7.592E-1 


$\begin{array}{clllcc}\text { REGION } & \text { E-LOWER } & \text { E-UPPER } & \text { EXPT } & \text { CALC } & \text { (C-E) / E (PCT.) } \\ 1 & 4.64 \mathrm{E}-1 & 1.00 \mathrm{E}+0 & 0.462 & 0.441 & -4.5 \\ 2 & 1.00 \mathrm{E}+0 & 2.15 \mathrm{E}+0 & 0.453 & 0.443 & -2.3 \\ 3 & 2.15 \mathrm{E}+0 & 4.64 \mathrm{E}+0 & 0.527 & 0.580 & 10.1 \\ 4 & 4.64 \mathrm{E}+0 & 1.00 \mathrm{E}+1 & 0.179 & 0.207 & 15.4 \\ 5 & 1.00 \mathrm{E}+1 & 2.15 \mathrm{E}+1 & 0.233 & 0.261 & 11.9 \\ 6 & 2.15 \mathrm{E}+1 & 4.64 \mathrm{E}+1 & 0.324 & 0.312 & -3.6 \\ 7 & 4.64 \mathrm{E}+1 & 1.00 \mathrm{E}+2 & 0.420 & 0.398 & -5.2 \\ 8 & 1.00 \mathrm{E}+2 & 2.15 \mathrm{E}+2 & 0.524 & 0.527 & 0.5 \\ 9 & 2.15 \mathrm{E}+2 & 4.64 \mathrm{E}+2 & 0.613 & 0.605 & -1.4 \\ 10 & 4.64 \mathrm{E}+2 & 1.00 \mathrm{E}+3 & 0.703 & 0.702 & -0.2 \\ 11 & 1.00 \mathrm{E}+3 & 2.15 \mathrm{E}+3 & 0.773 & 0.759 & -1.8\end{array}$

CASE 5. SAMPLE THICKNESS IS 9.473 GMS/CM**2 U.

REGION 1, SHIELDED=6.815E+0, UNSHIELDED=4.995E+1, RATHO=1.364E-1 REGION 2, SHIELDED $=4.966 \mathrm{E} \div 0$, UNSHIELDED $=2.751 \mathrm{E}+1$, RATIO=1.805E-1 REGION 3, SHIELDED=4.056E+0, UNSHIELDED=1.291E+1, RATIO=3.141E-1 REGION 4, SHIELDED $=3.065 \mathrm{E}+0$, UNSHIELDED $=3.595 \mathrm{E}+1, \mathrm{RATIO}=8.526 \mathrm{E}-2$ REGION 5, SHIELDED $=4.261 \mathrm{E}+0$, UNSHIELDED=3.782E +1 , RATIO=1.127E- 1 REGION 6, SHIELDED $=4.063 \mathrm{E}+0$, UNSHIELDED $=3.225 \mathrm{E}+1$, RATIO=1.260E-1 REGION 7, SHIELDED $=4.323 E+0$, UNSHIELDED $=2.659 \mathrm{E}+1$, RATIO=1.626E-1 REGION 8, SHIELDED=3.967E+0, UNSHIELDED $=1.578 E+1$, RATIO=2.515E-1. REGION 9, SHIELDED=4.140E+0, UNSHIELDED $=1.266 \mathrm{E}+1, \mathrm{RATIO}=3.270 \mathrm{E}-1$ REGION 10, SHIELDED=3.718E+0, UNSHIELDED=8.590E+0, RATIO=4.329E-1 REGION 11, SHIELDED=2.820E+0, UNSHIELDED=5.473E+0, RATIO=5.152E-1

$\begin{array}{cllllc}\text { REGION } & \text { E-LOWER } & \text { E-UPPER } & \text { EXPT } & \text { CALC } & \text { (C-E) /E (PCT.) } \\ 1 & 4.64 \mathrm{E}-1 & 1.00 \mathrm{E}+0 & 0.152 & 0.136 & -10.2 \\ 2 & 1.00 \mathrm{E}+0 & 2.15 \mathrm{E}+0 & 0.199 & 0.181 & -9.3 \\ 3 & 2.15 \mathrm{E}+0 & 4.64 \mathrm{E}+0 & 0.286 & 0.314 & 9.8 \\ 4 & 4.64 \mathrm{E}+0 & 1.00 \mathrm{E}+1 & 0.070 & 0.085 & 21.8 \\ 5 & 1.00 \mathrm{E}+1 & 2.15 \mathrm{E}+1 & 0.103 & 0.113 & 9.4 \\ 6 & 2.15 \mathrm{E}+1 & 4.64 \mathrm{E}+1 & 0.131 & 0.126 & -3.8 \\ 7 & 4.64 \mathrm{E}+1 & 1.00 \mathrm{E}+2 & 0.183 & 0.163 & -11.1 \\ 8 & 1.00 \mathrm{E}+2 & 2.15 \mathrm{E}+2 & 0.260 & 0.251 & -3.3 \\ 9 & 2.15 \mathrm{E}+2 & 4.64 \mathrm{E}+2 & 0.336 & 0.327 & -2.7 \\ 10 & 4.64 \mathrm{E}+2 & 1.00 \mathrm{E}+3 & 0.440 & 0.433 & -1.6 \\ 11 & 1.00 \mathrm{E}+3 & 2.15 \mathrm{E}+3 & 0.542 & 0.515 & -4.9\end{array}$

CASE 6. SAMPLE THICKNESS IS $19.04 \mathrm{GMS} / \mathrm{CM}^{* * 2} \mathrm{U}$.

REGION 1, SHIELDED=9.751E-1, UNSHIELDED $=4.995 \mathrm{E}+1, \mathrm{RATIO}=1.952 \mathrm{E}-2$

REGION 2, SHIELDED $=1.707 \mathrm{E}+0$, UNSHIELDED $=2.751 \mathrm{E}+1$, RATIO=6.203E -2 
REGION 3, SHIELDED=1.777E+0, UNSHIELDED=1.291E+1, RATIO=1.376E-1 REGION 4, SHIELDED=1.112E+0, UNSHIELDED=3.595E+1, RATIO=3.093E-2 REGION 5, SHIELDED $=1.457 \mathrm{E}+0$, UNSHIELDED $=3.782 \mathrm{E}+1$, RATTO=3.854E-2 REGION 6, SHIELDED $=1.317 \mathrm{E}+0$, UNSHIELDED $=3.225 \mathrm{E}+1, \mathrm{RATIO}=4.083 \mathrm{E}-2$ REGION 7, SHIELDED=1.463E+0, UNSHIELDED=2.659E +1, RATIO=5.504E-2 REGION 8, SHIELDED $=1.477 \mathrm{E}+0$, UNSHIELDED $=1.578 \mathrm{E}+1$, RATIO=9.365E-2 REGION 9, SHIELDED=1.737E+0, UNSHELDED=1.266E +1, RATIO=1.372E-1 REGION 10, SHIELDED $=1.752 \mathrm{E}+0$, UNSHIELDED $=8.590 \mathrm{E}+0$, RATIO $=2.040 \mathrm{E}-1$ REGION 11, SHIELDED=1.507E+0, UNSHIELDED=5.473E+0, RATIO=2.754E-1

\begin{tabular}{clllll} 
REGION & E-LOWER & E-UPPER & EXPT & CALC & (C-E) / E (PCT.) \\
1 & $4.64 \mathrm{E}-1$ & $1.00 \mathrm{E}+0$ & 0.028 & 0.020 & -30.3 \\
2 & $1.00 \mathrm{E}+0$ & $2.15 \mathrm{E}+0$ & 0.072 & 0.062 & -13.8 \\
3 & $2.15 \mathrm{E}+0$ & $4.64 \mathrm{E}+0$ & 0.138 & 0.138 & -0.3 \\
4 & $4.64 \mathrm{E}+0$ & $1.00 \mathrm{E}+1$ & 0.025 & 0.031 & 23.7 \\
5 & $1.00 \mathrm{E}+1$ & $2.15 \mathrm{E}+1$ & 0.034 & 0.039 & 13.3 \\
6 & $2.15 \mathrm{E}+1$ & $4.64 \mathrm{E}+1$ & 0.043 & 0.041 & -5.0 \\
7 & $4.64 \mathrm{E}+1$ & $1.00 \mathrm{E}+2$ & 0.067 & 0.055 & -17.9 \\
8 & $1.00 \mathrm{E}+2$ & $2.15 \mathrm{E}+2$ & 0.099 & 0.094 & -5.4 \\
9 & $2.15 \mathrm{E}+2$ & $4.64 \mathrm{E}+2$ & 0.159 & 0.137 & -13.7 \\
10 & $4.64 \mathrm{E}+2$ & $1.00 \mathrm{E}+3$ & 0.214 & 0.204 & -4.7 \\
11 & $1.00 \mathrm{E}+3$ & $2.15 \mathrm{E}+3$ & 0.302 & 0.275 & -8.8 \\
\hline
\end{tabular}


APPENDIX H. REGION-AVERAGED RADIATION WIDTHS IN RELEASE 3

\begin{tabular}{|c|c|c|c|c|}
\hline REGION & $\begin{array}{c}\text { EMIN } \\
\mathrm{eV}\end{array}$ & $\begin{array}{c}\text { EMAX } \\
\mathrm{eV}\end{array}$ & $\begin{array}{c}\text { No. of } \\
\text { resonances }\end{array}$ & $\begin{array}{c}\text { Average } \Gamma_{\mathrm{Y}} \\
\mathrm{meV}\end{array}$ \\
\hline 1 & 0 & 4 & 7 & 37.84 \\
\hline 2 & 4 & 110 & 194 & 38.21 \\
\hline 3 & 110 & 300 & 343 & 56.53 \\
\hline 4 & 300 & 500 & 362 & 53.81 \\
\hline 5 & 500 & 750 & 330 & 43.79 \\
\hline 6 & 750 & 1000 & 269 & 45.29 \\
\hline
\end{tabular}

The average from $0-110 \mathrm{eV}$ is $38.20 \mathrm{meV}$, obtained by adjusting Release 2 to the Perez/de Saussure values, as described above. Moxon's recommended value of $38.2 \mathrm{meV}$ was arrived at in an entirely independent procedure, so that the agreement, although fortuitously "exact", is nonetheless supportive of the present method.

In the above table, only the values below $110 \mathrm{eV}$ can be viewed as genuine widths. Above that, up to a kilovolt, where they run 40-50 meV, one might argue that they represent "clumps" of resonances. The procedure insures that the total and fission cross sections will look pretty much as they did in Release 2, while the capture looks as if it had been conventionally renormalized, i.e., as if the pointwise values had been multiplied by the bin-multipliers. 
Figure 1. Oak Ridge and Rocky Flats Solution Tank Experiments

ENDF/B-VI U235 Release 2 and 3 Eigenvalues vs. Above-Thermal Leakage

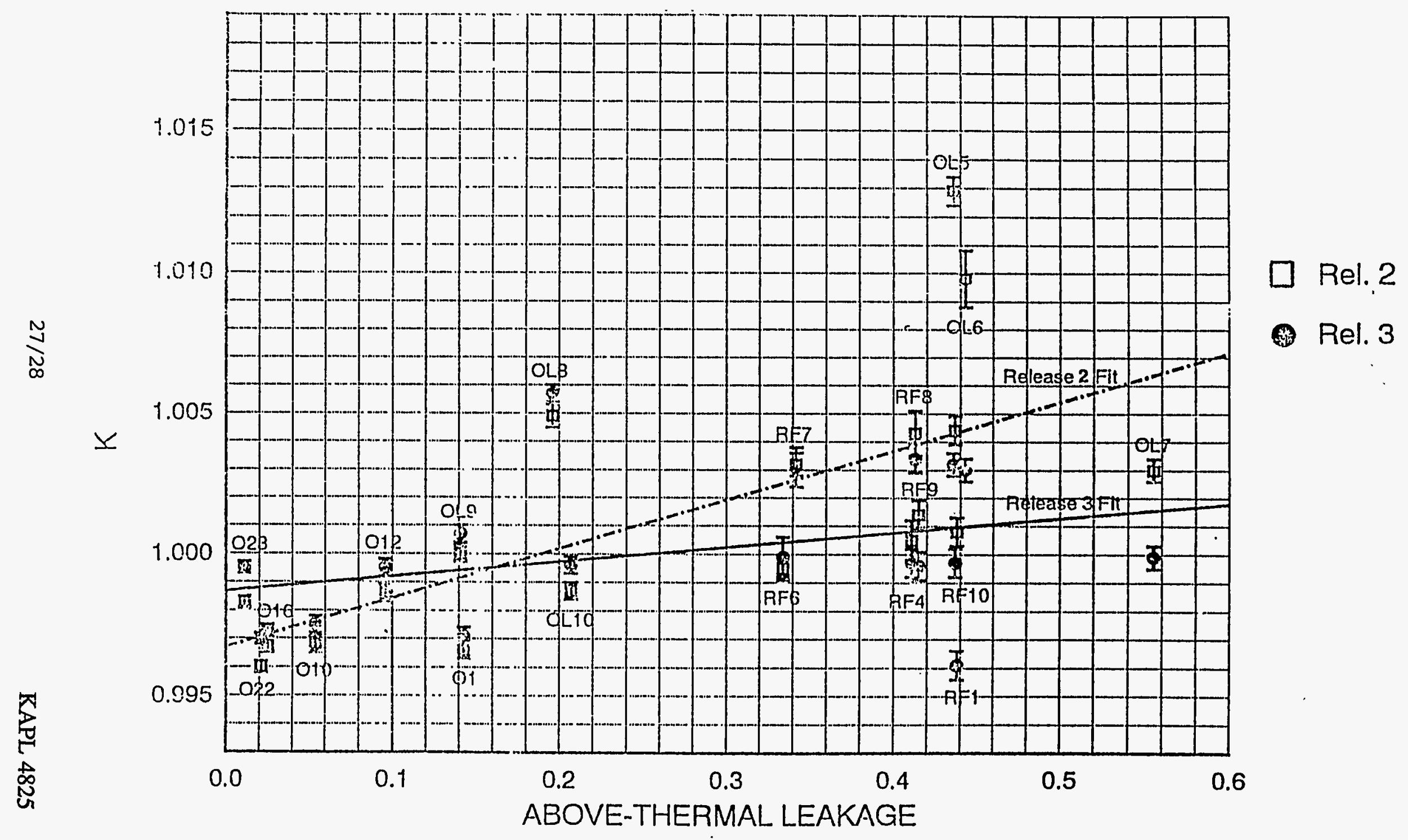




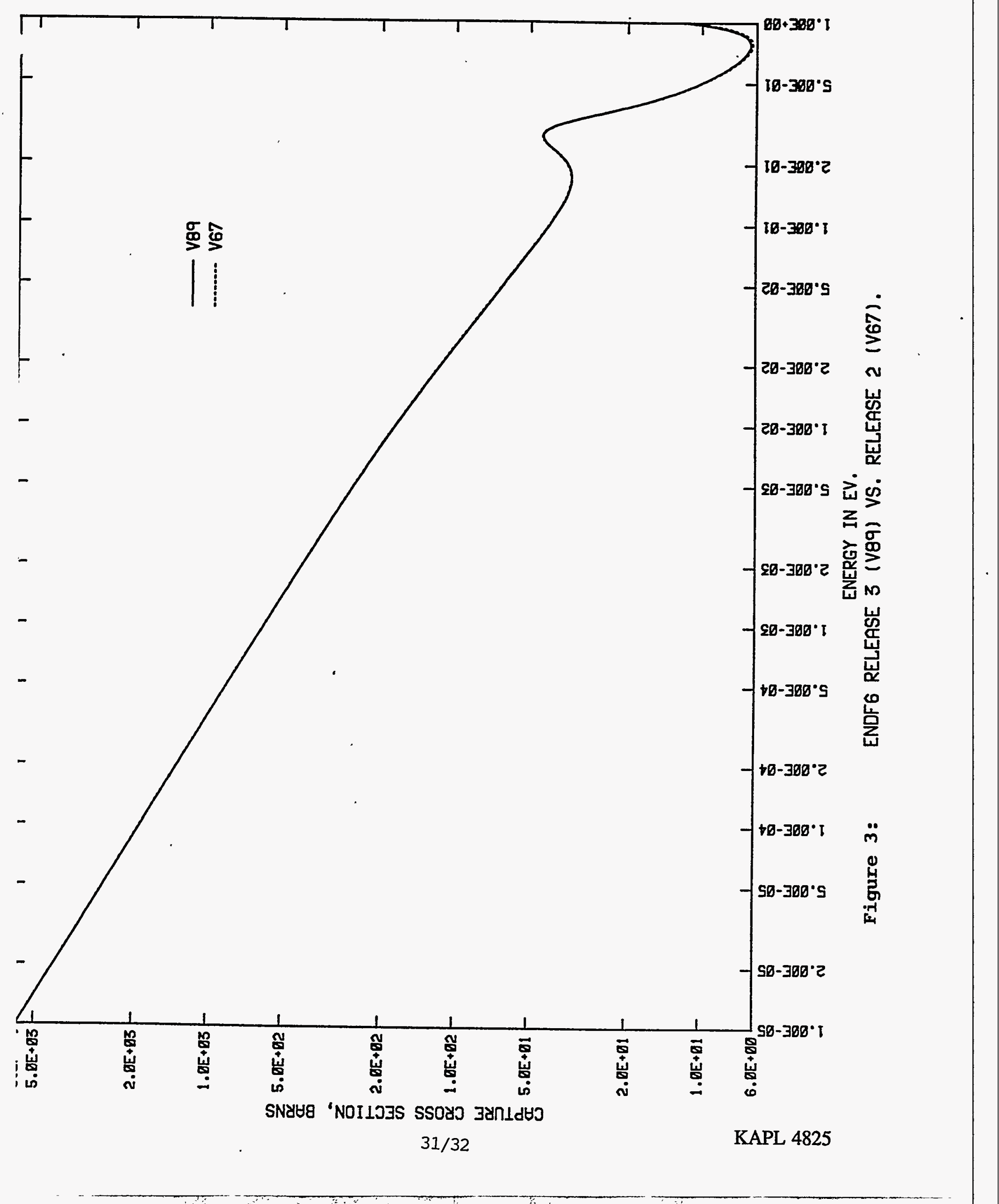




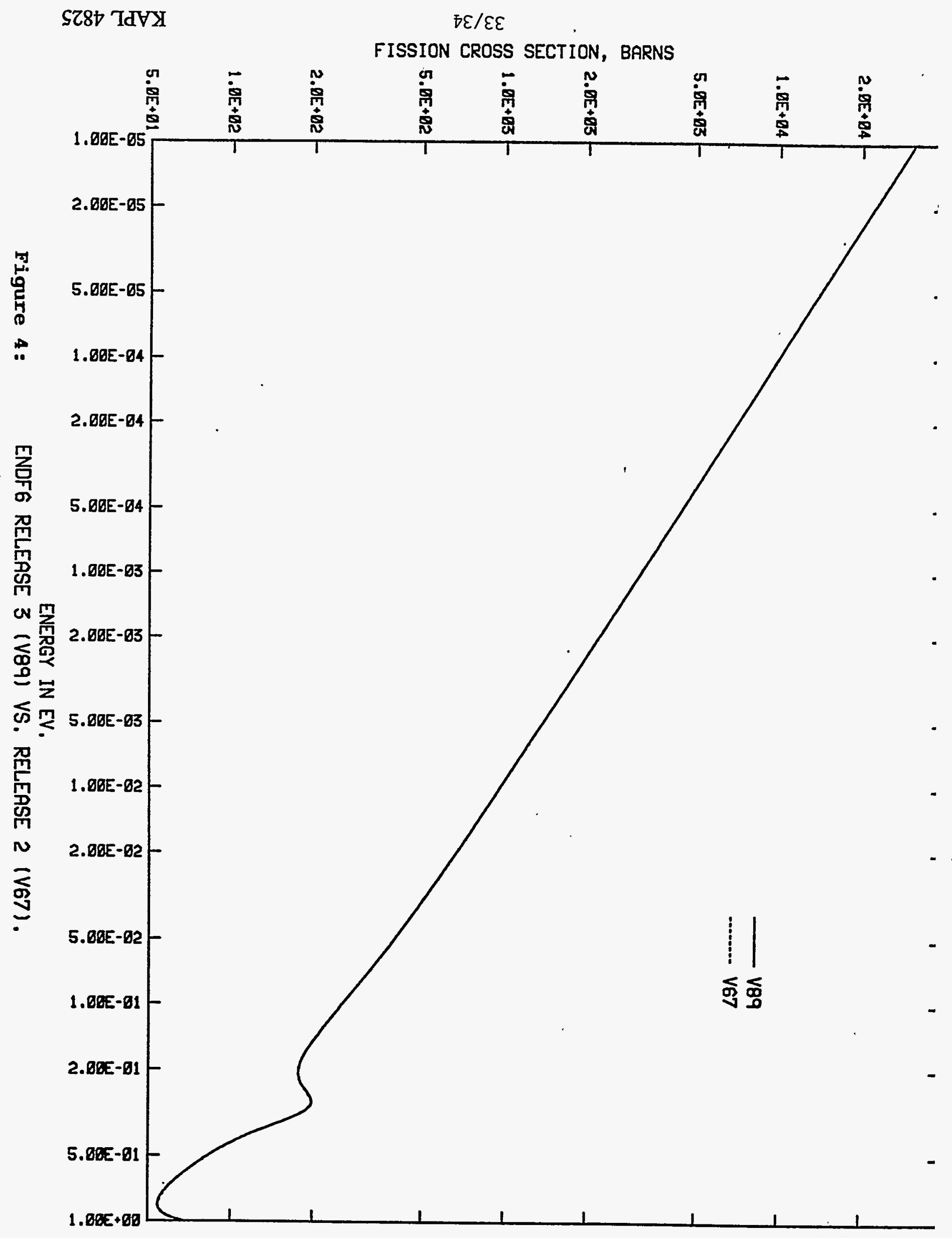




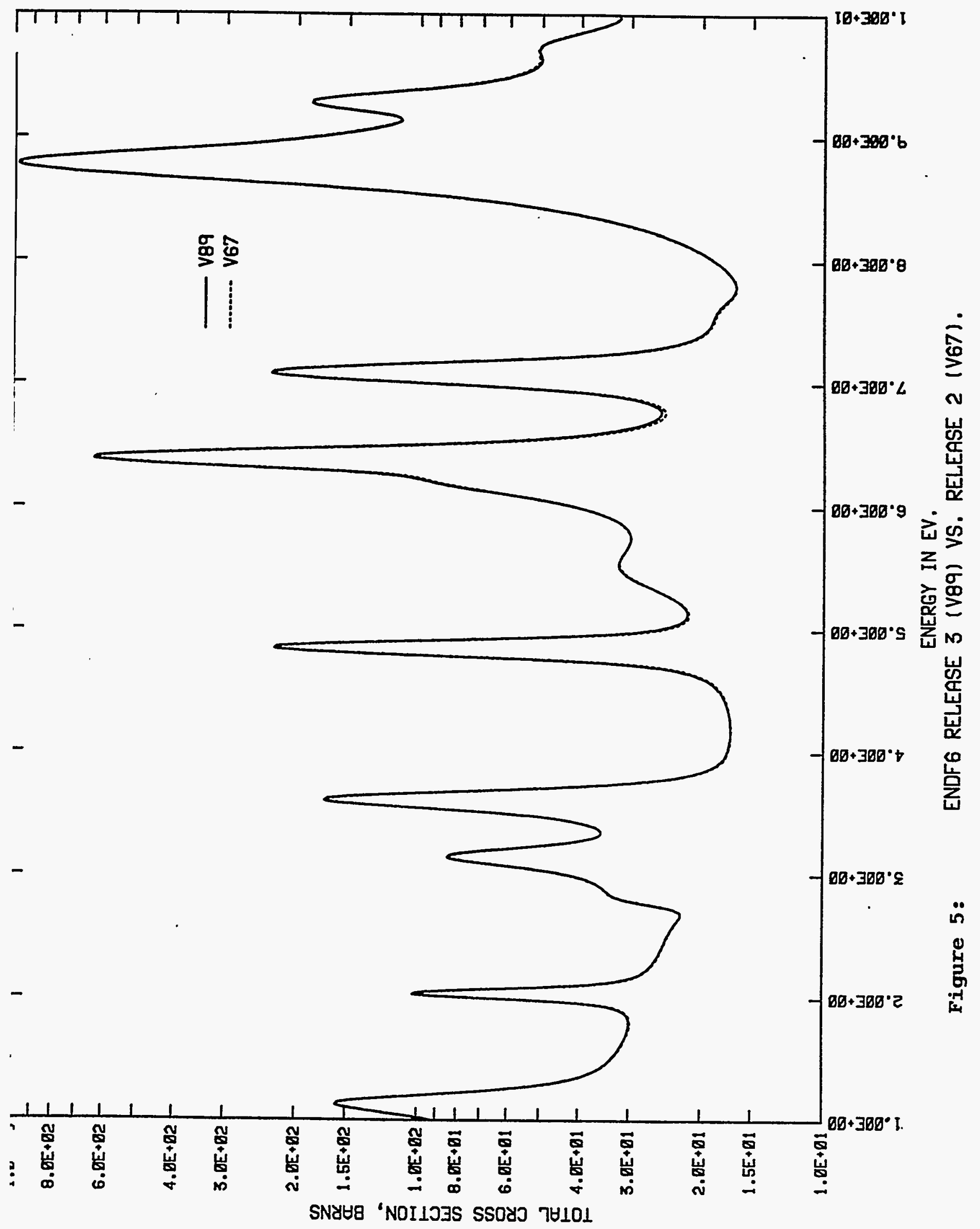




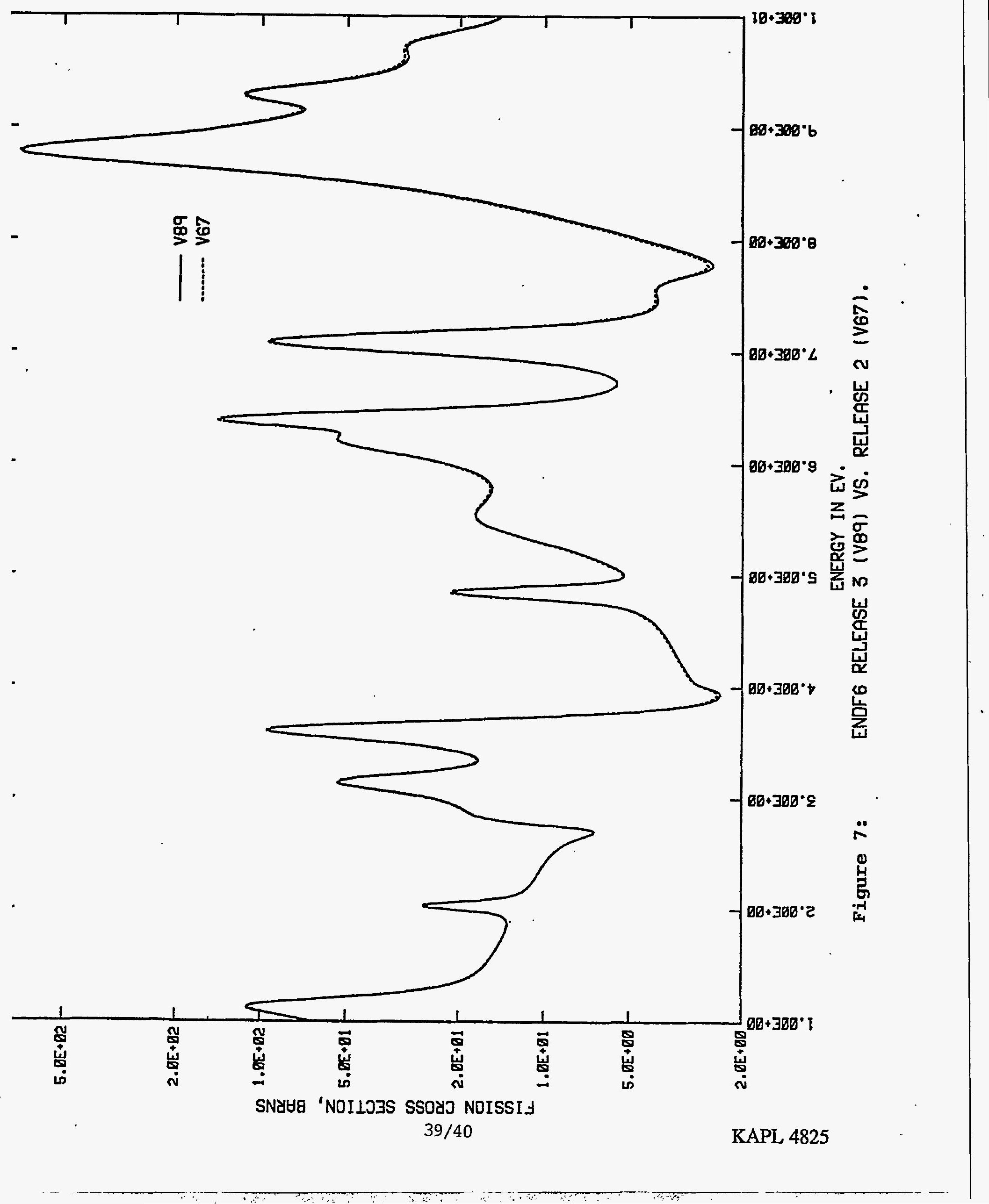




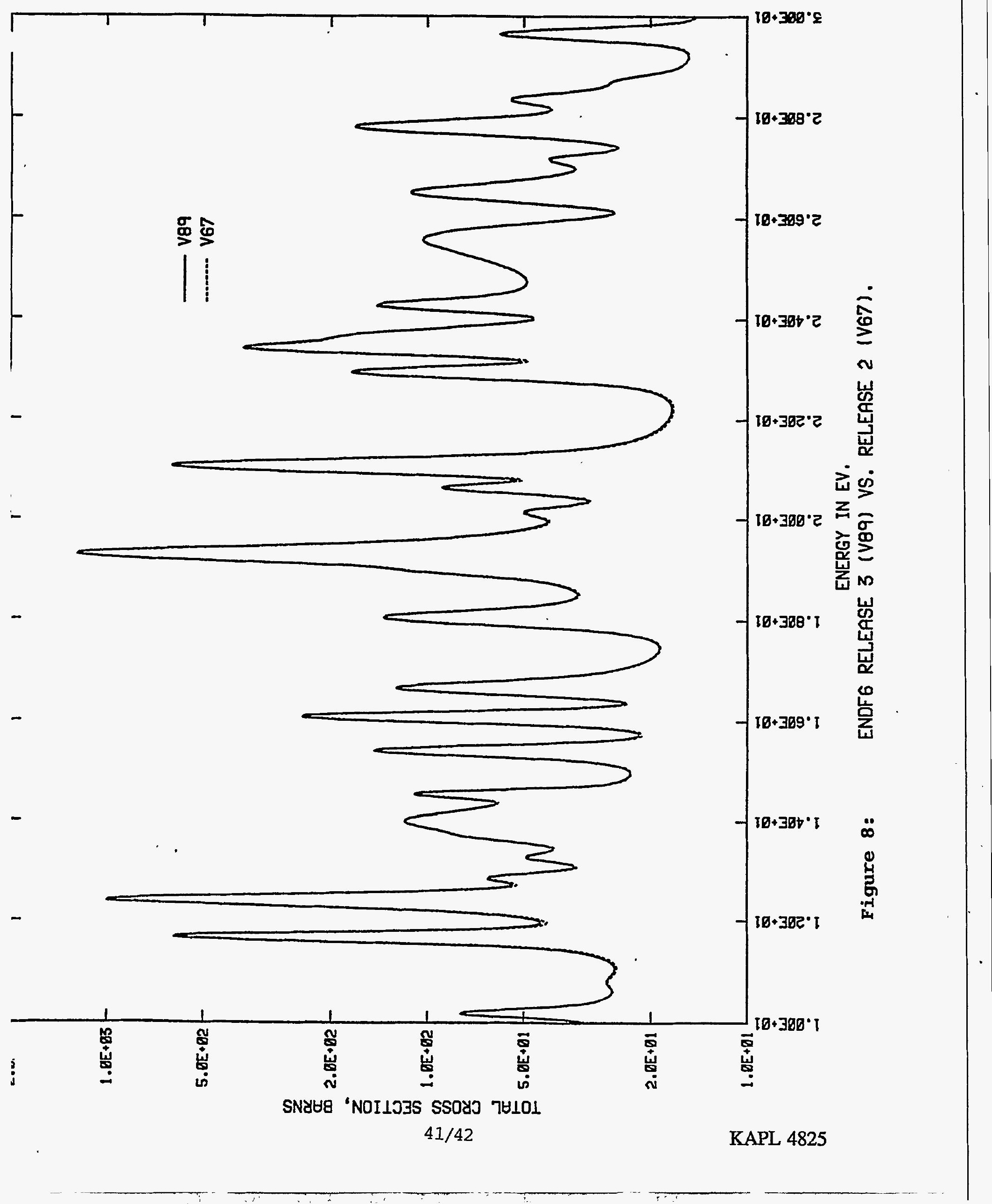




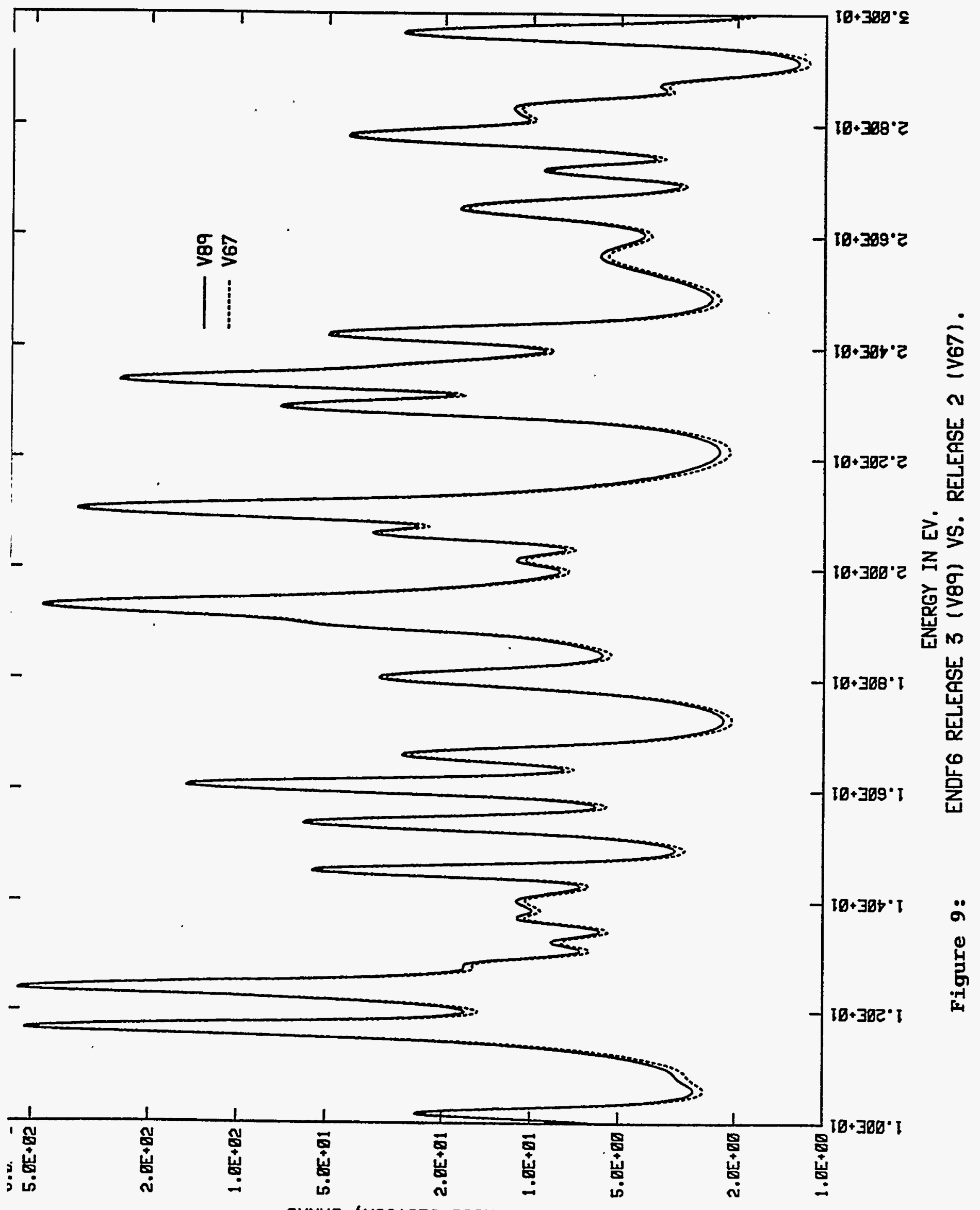

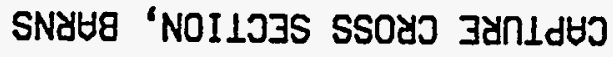




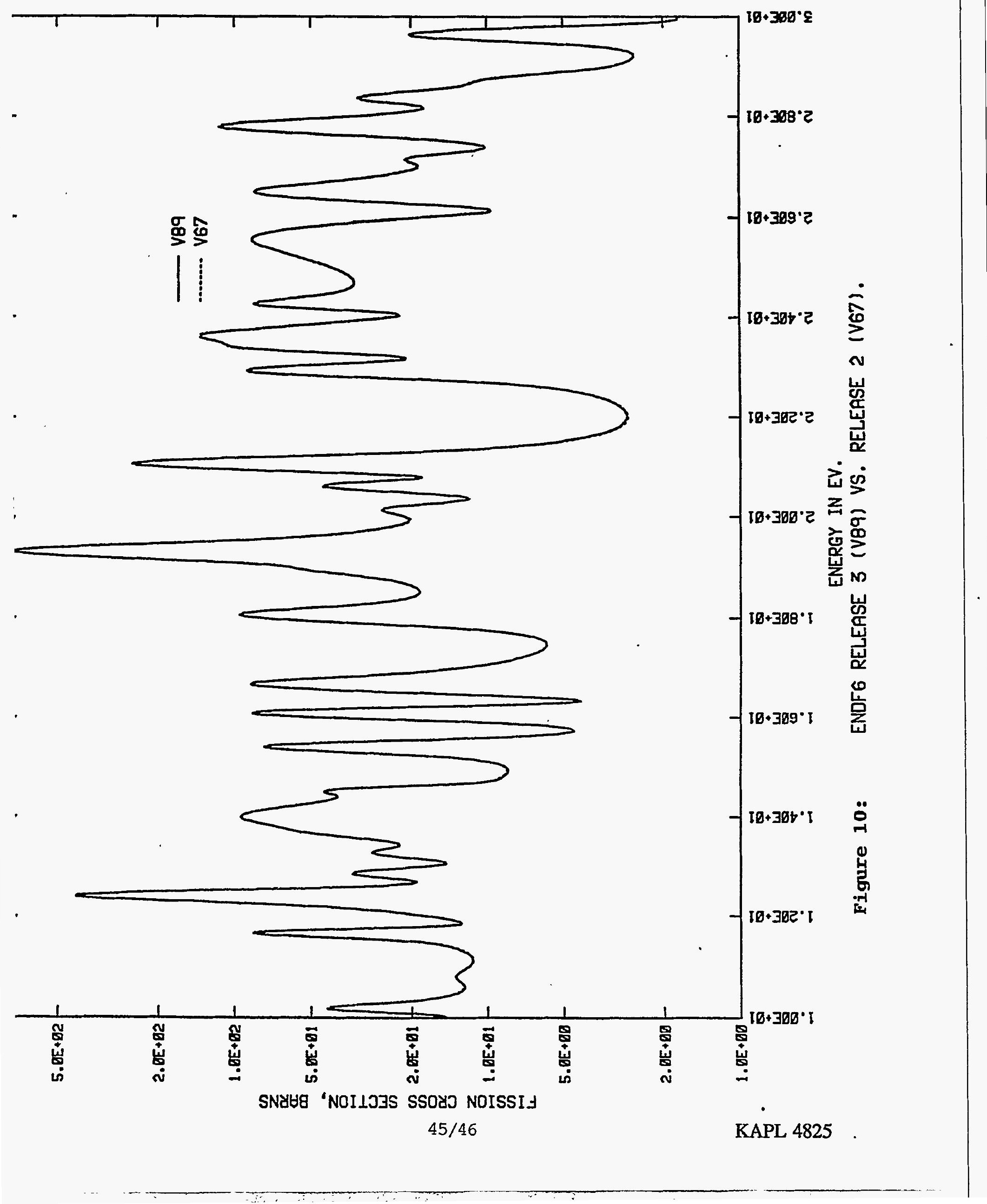


SZ8† TdVY

$87 / \angle 7$

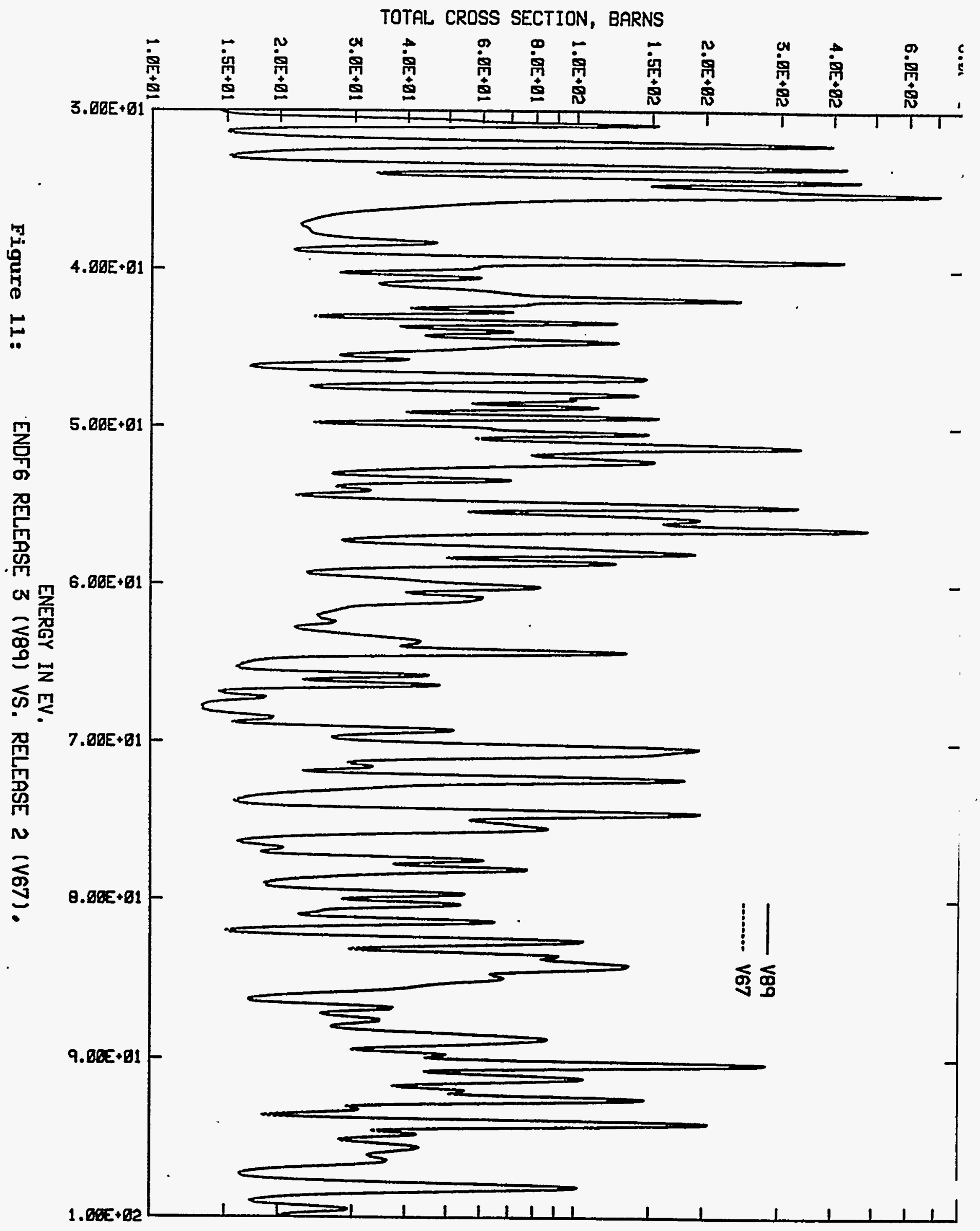




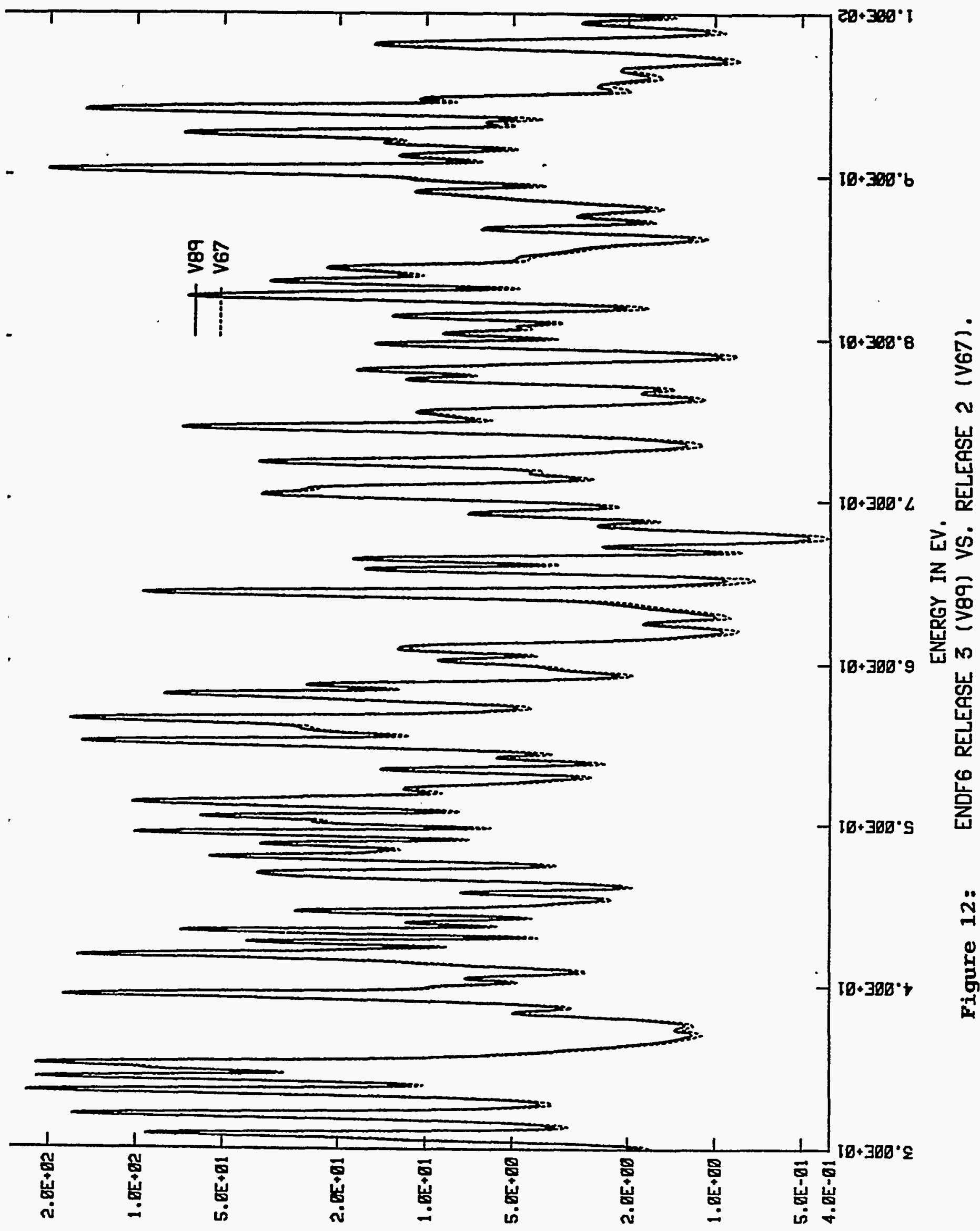

SNYUG 'NOILJJS SSOYJ JUחLIAJ 


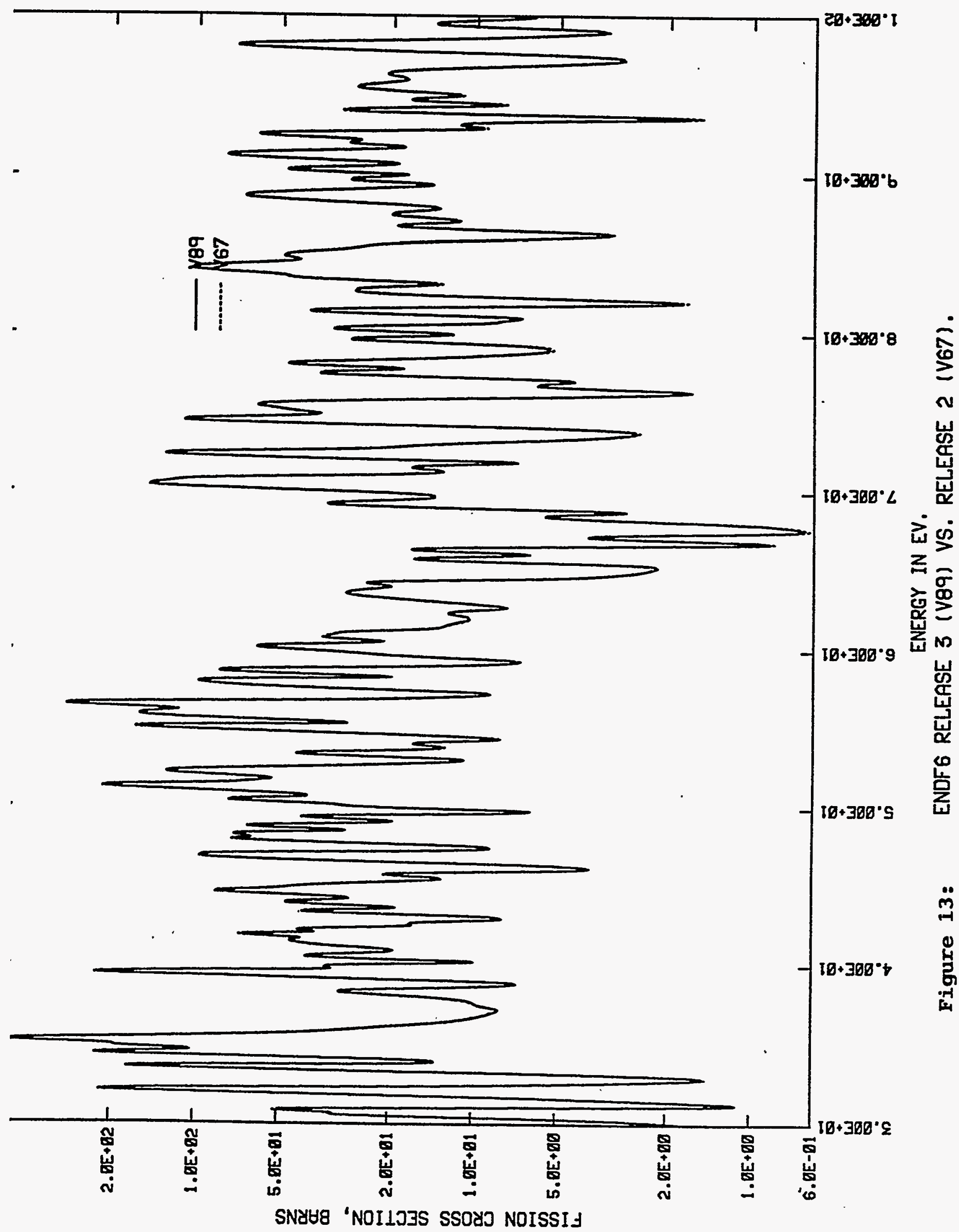

$$
51 / 52
$$




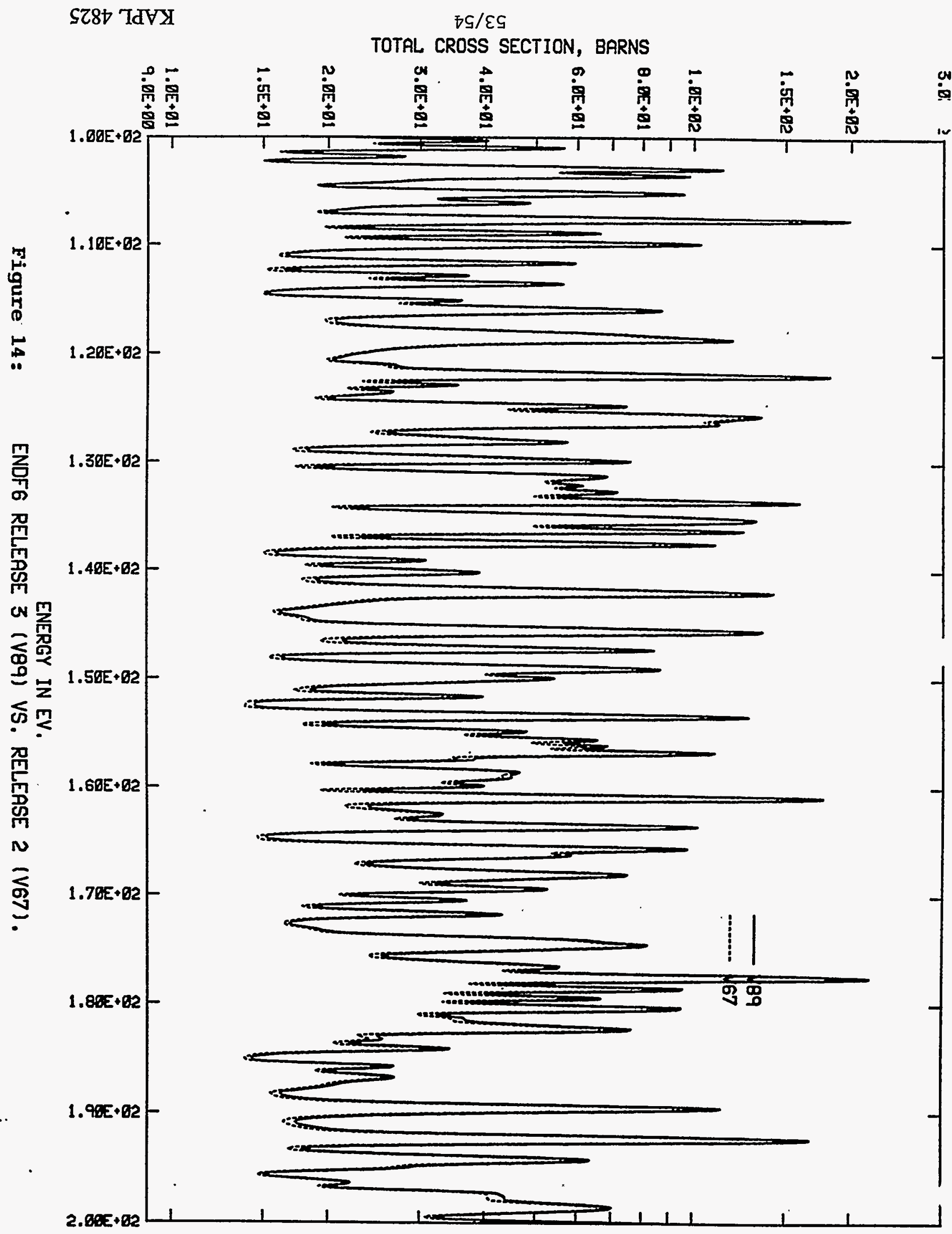




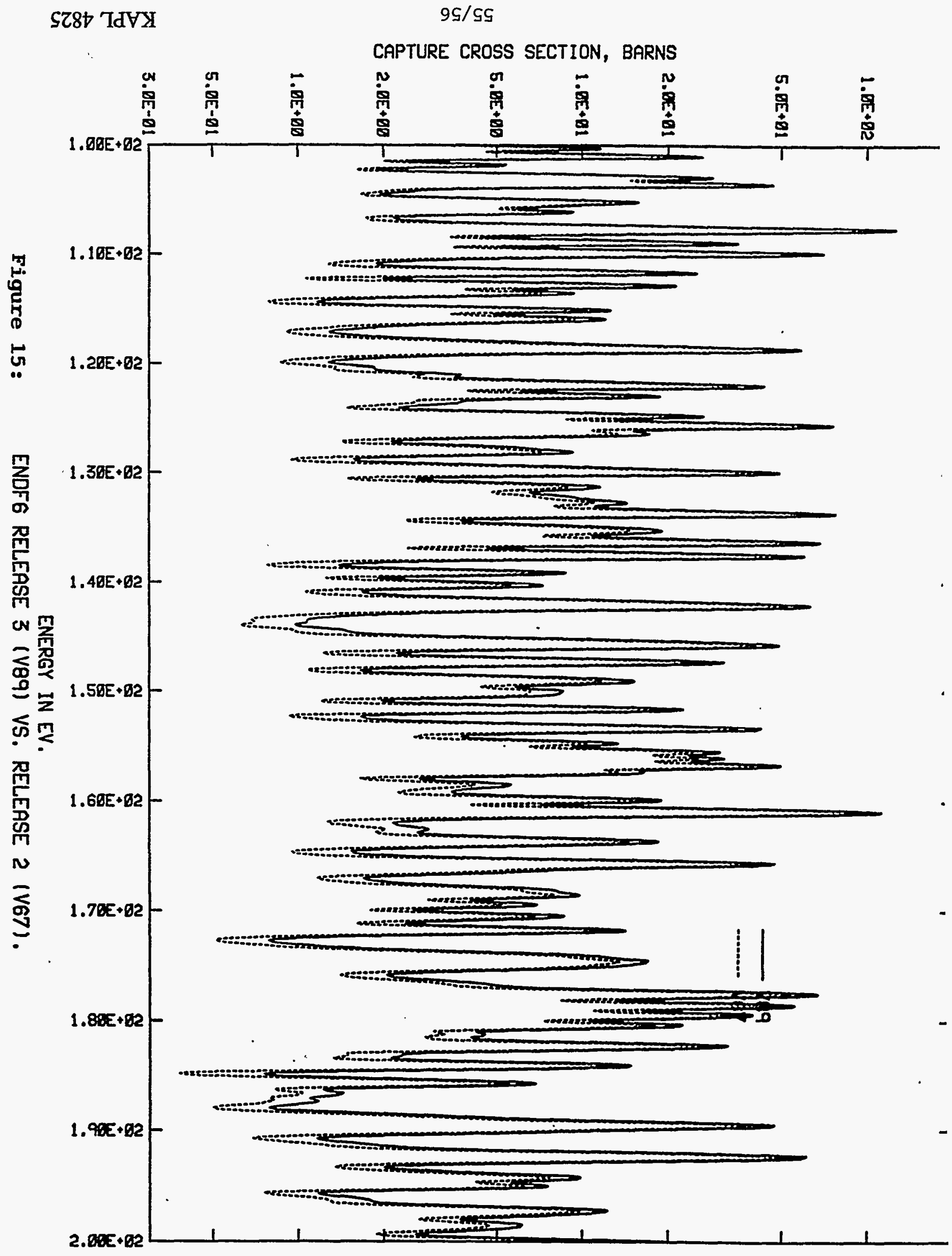




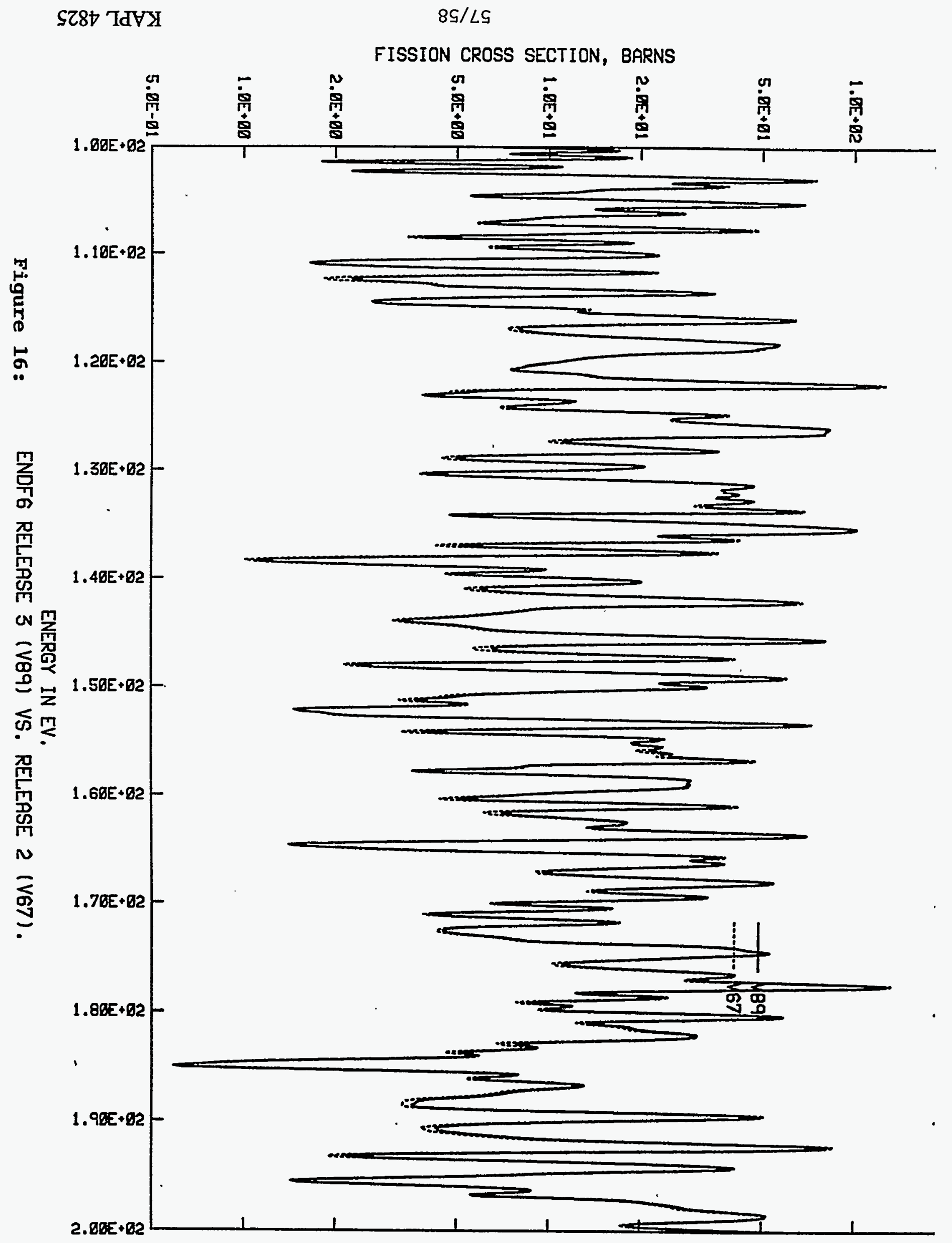




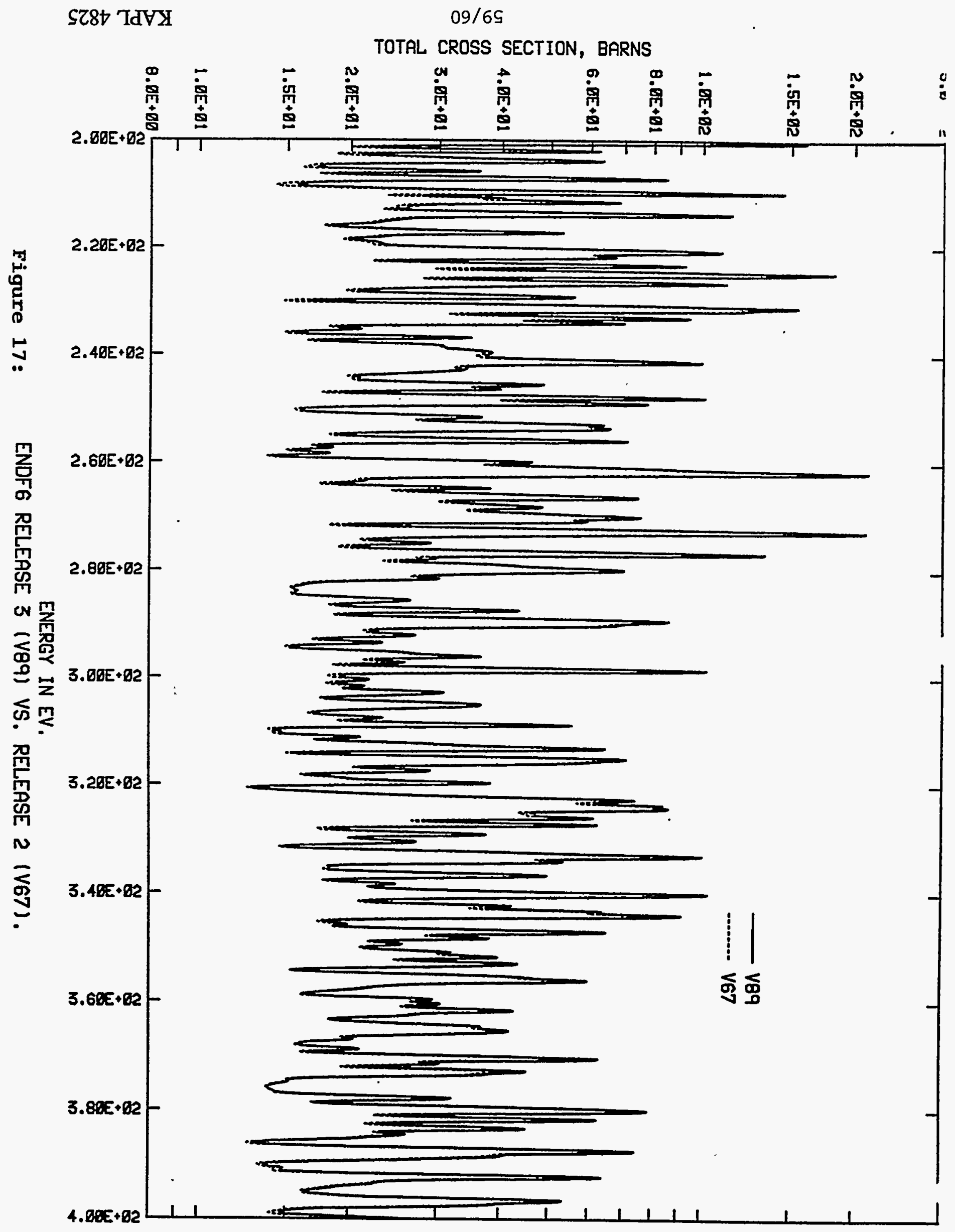




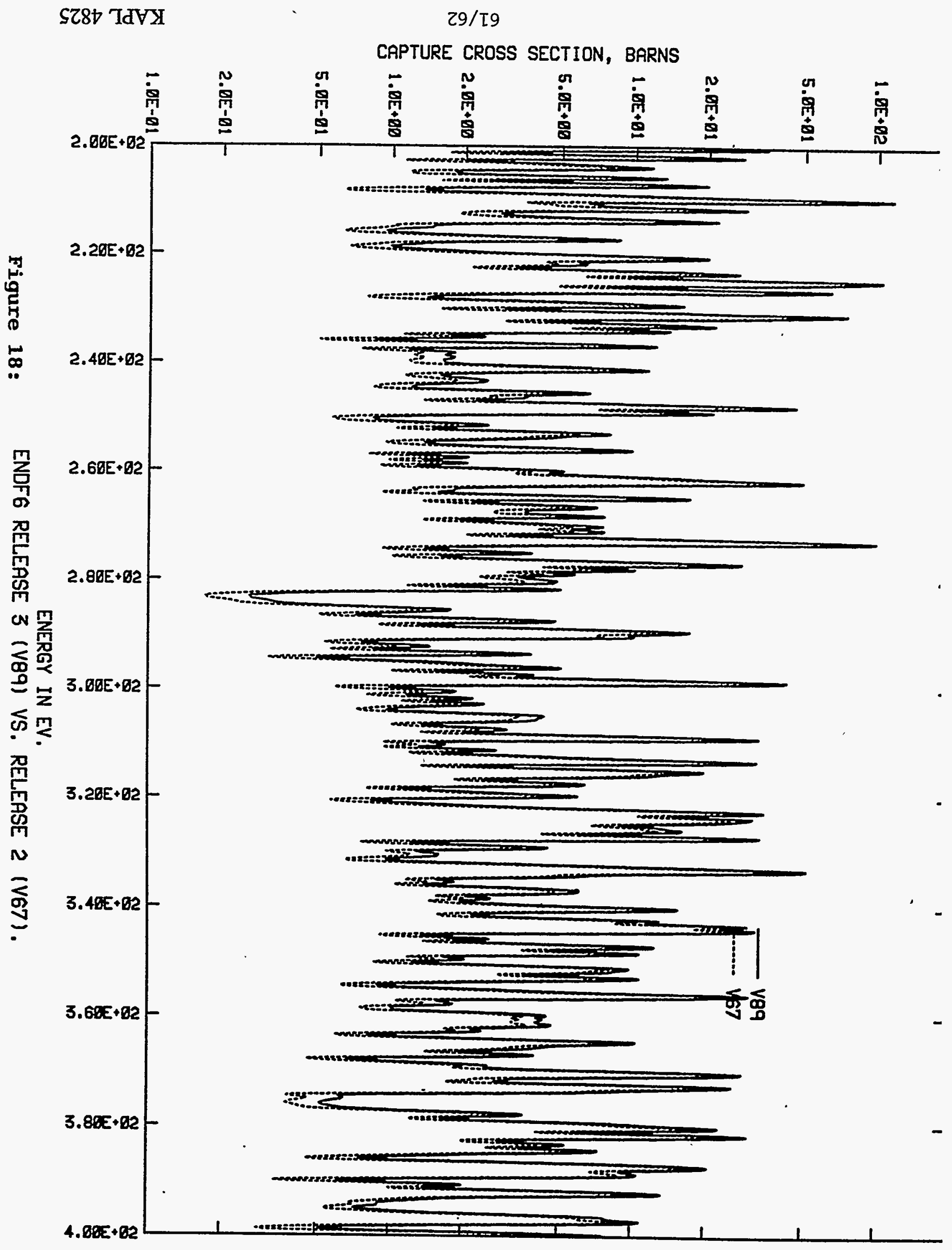


SZ8D TdVX

ๆ $9 / \varepsilon 9$

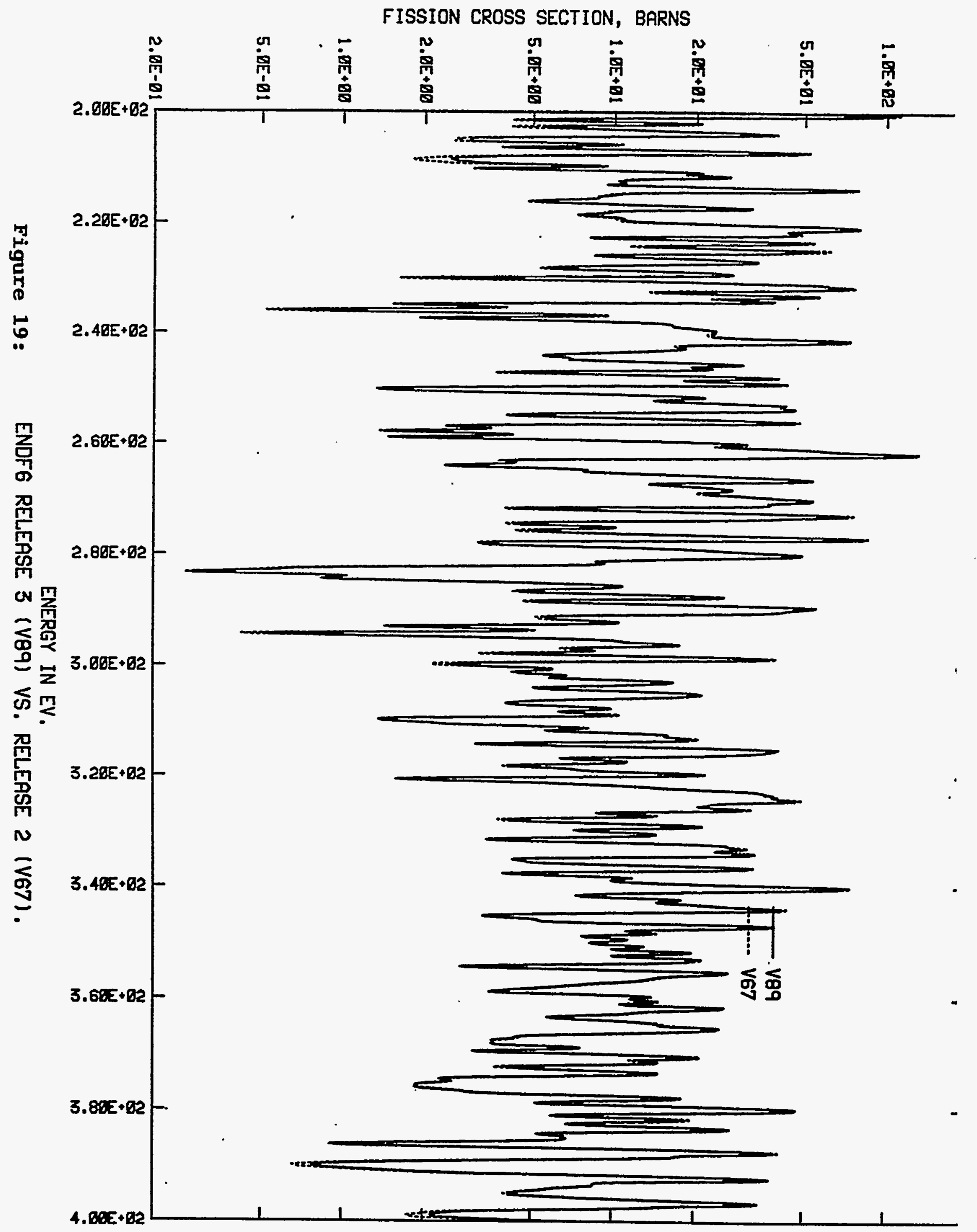




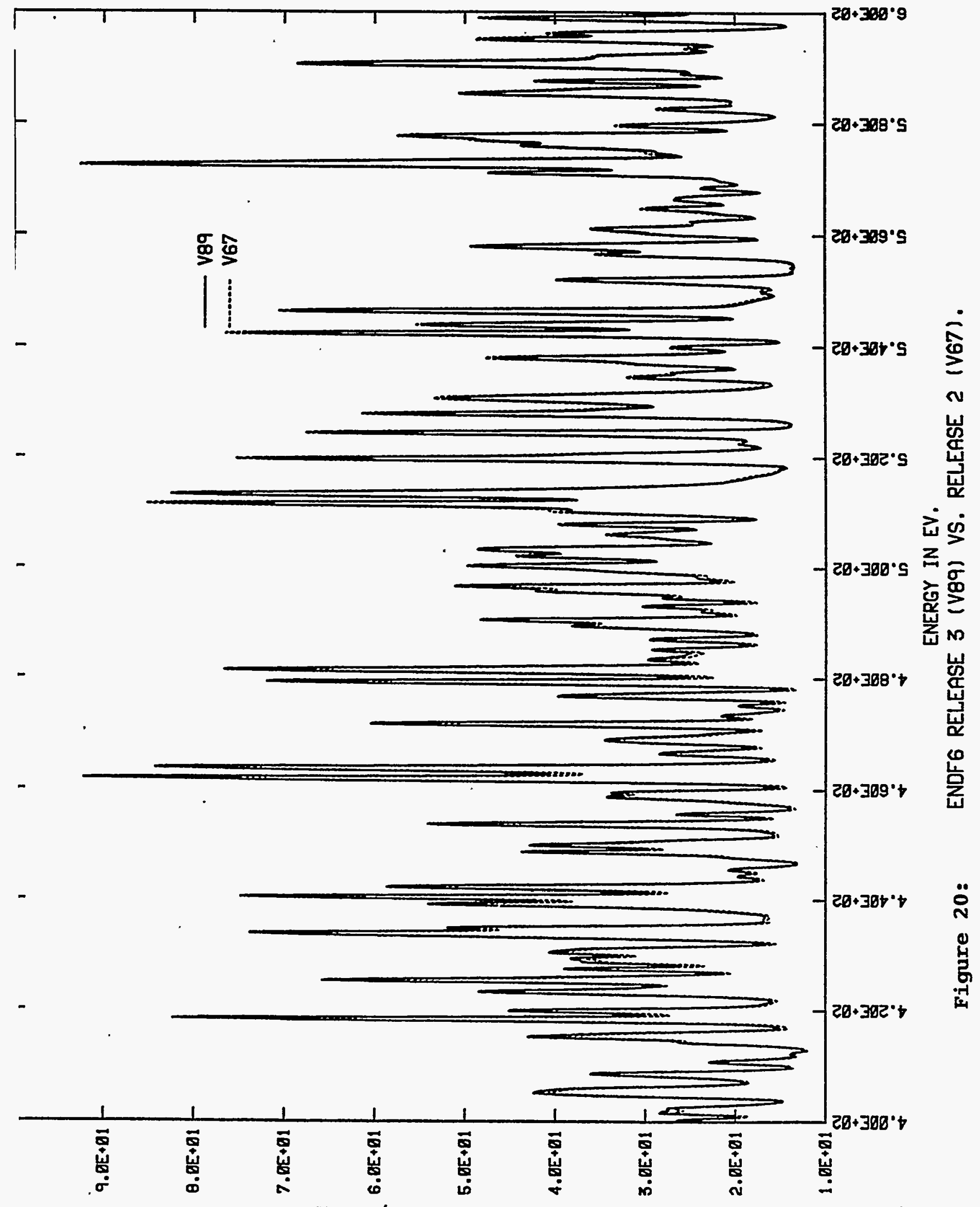

SNEUA 'NOILOJS SSOYJ 7 7101 


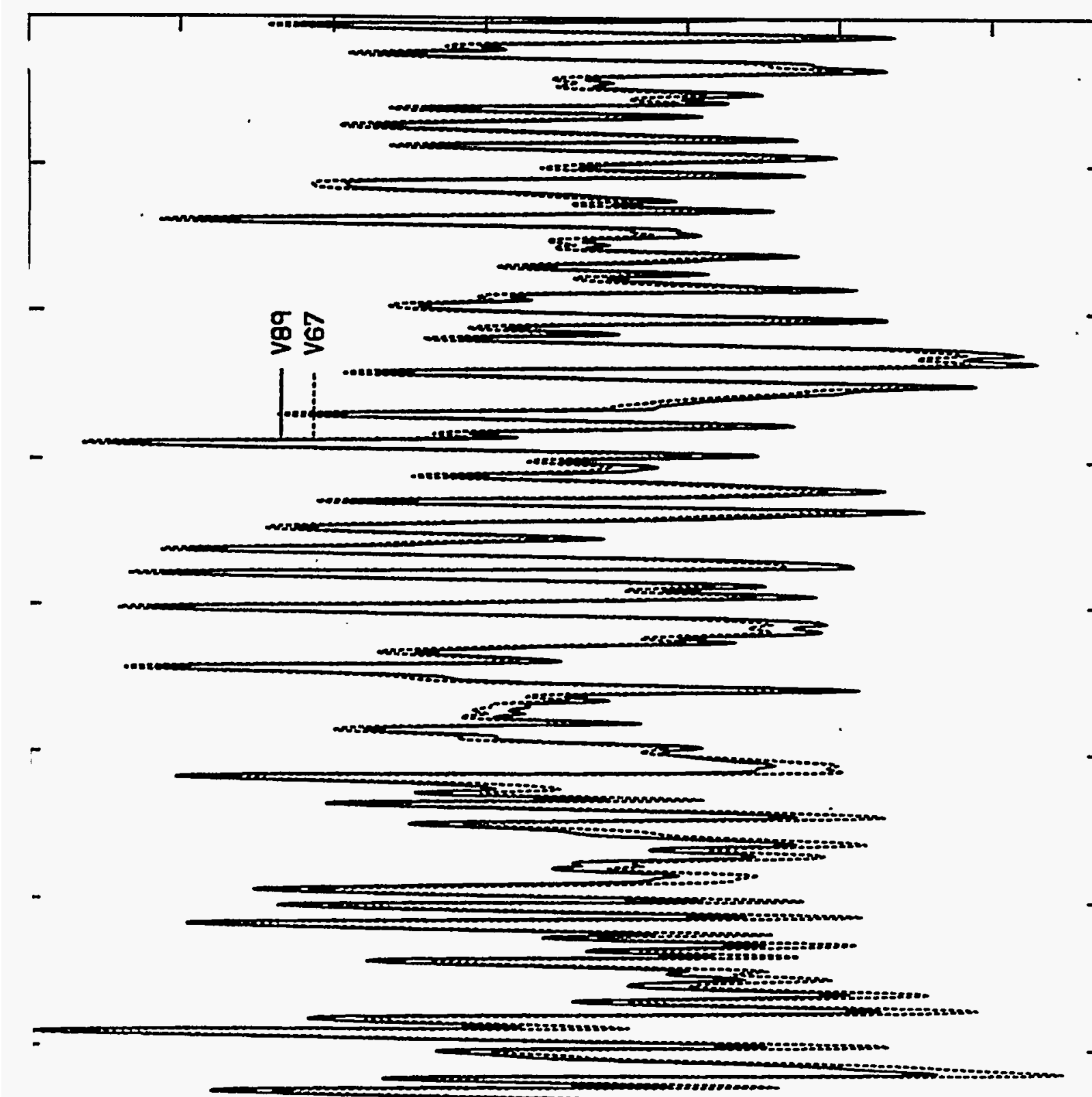

$28+330 \cdot 9$

$28+398 \cdot s$

$20+309 \cdot 5$

$20+307 \cdot 5$

$\stackrel{2}{2}$

$-20+302 \cdot 5$

N

峞

这

$20 \cdot 300 \cdot 5$

它

$20+388^{\circ} t$

$\sum \frac{2}{9}$

\%

己

嵌 $n$

崓

논

更

$20+389 \cdot 5$

$\infty$

늘

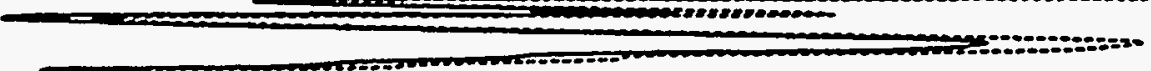

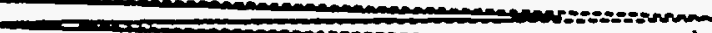

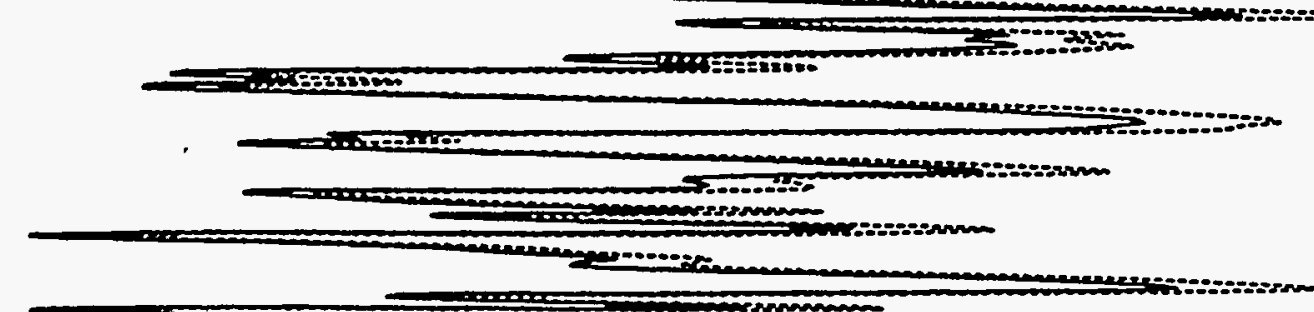

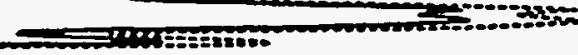

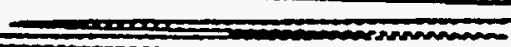

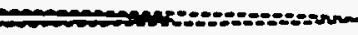

1 C

0 -

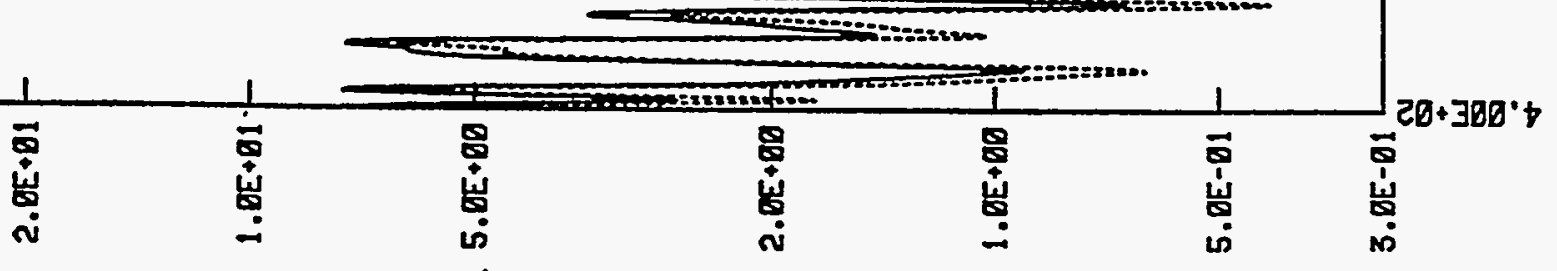

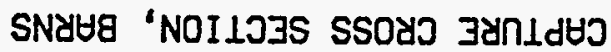


SZ8t TdVX

$0 L / 69$

FISSION CROSS SECTION, BARNS

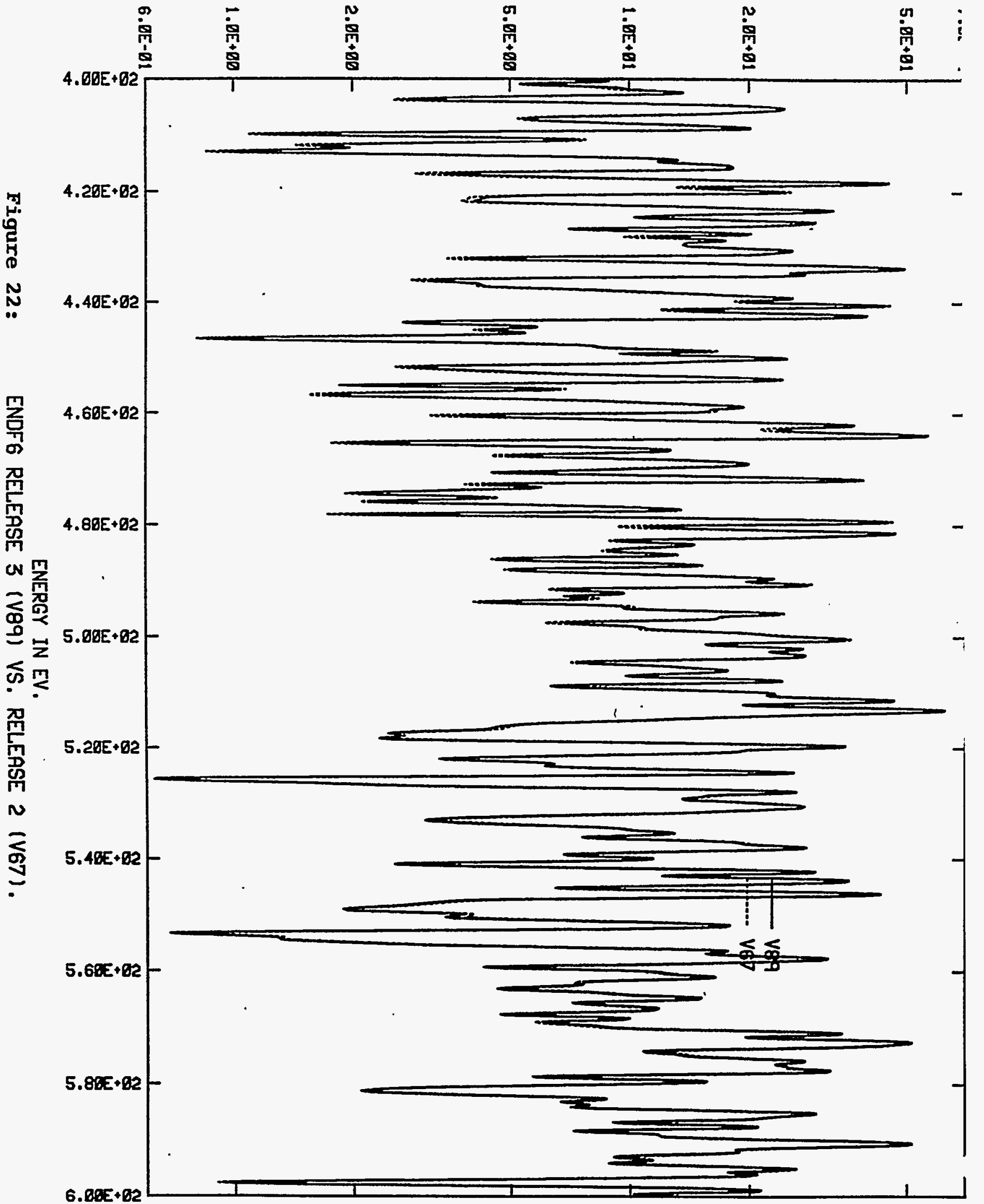




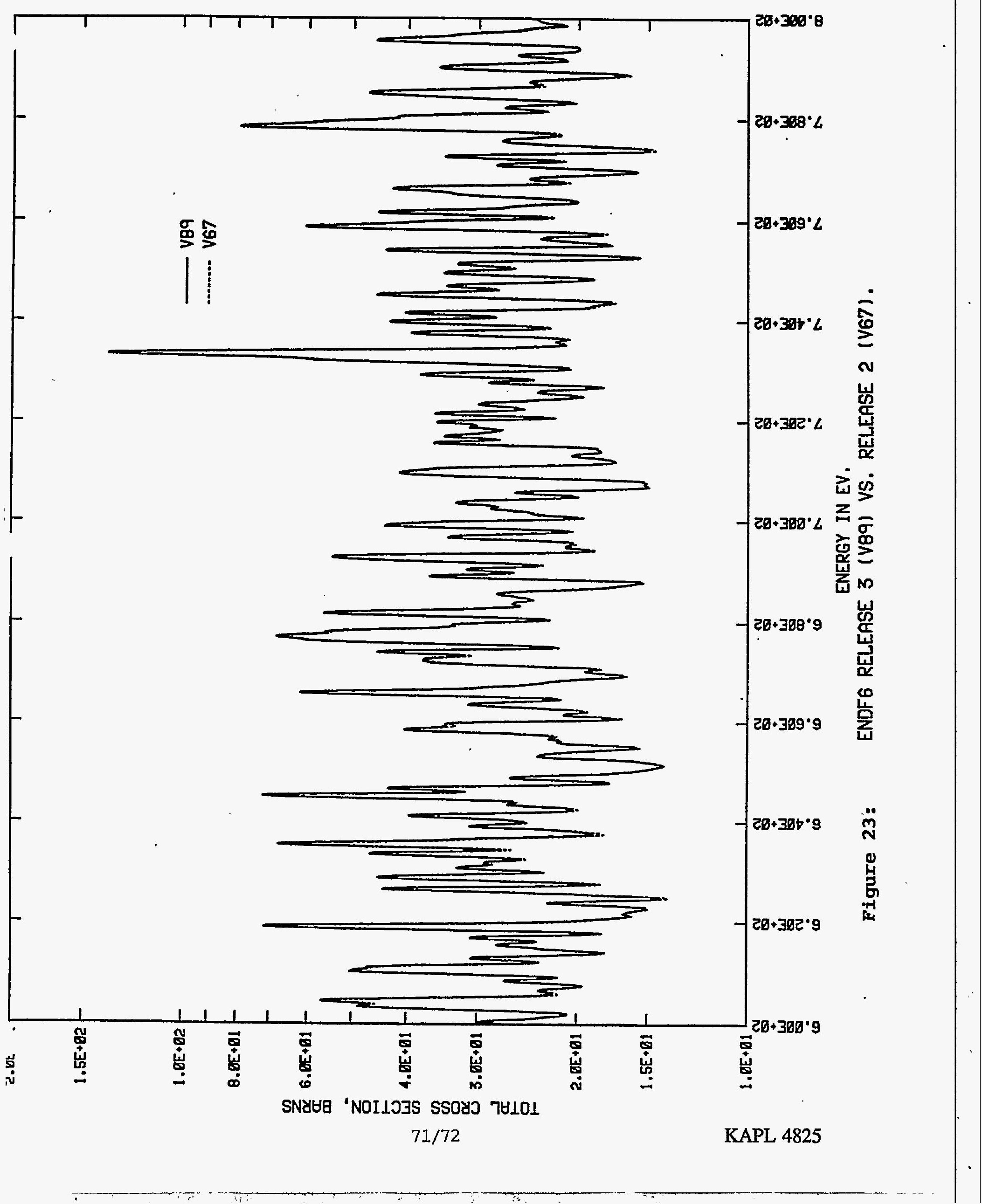




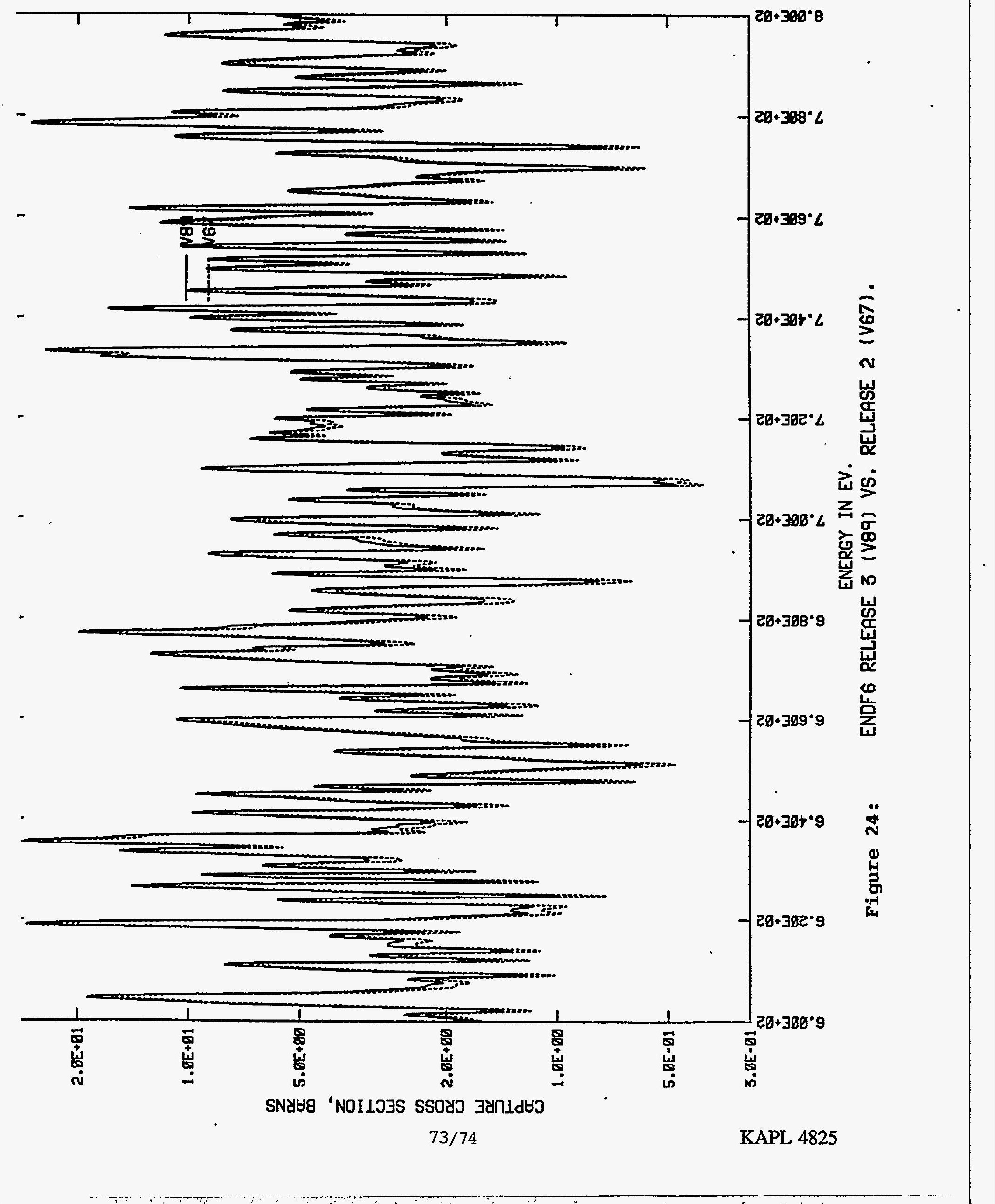




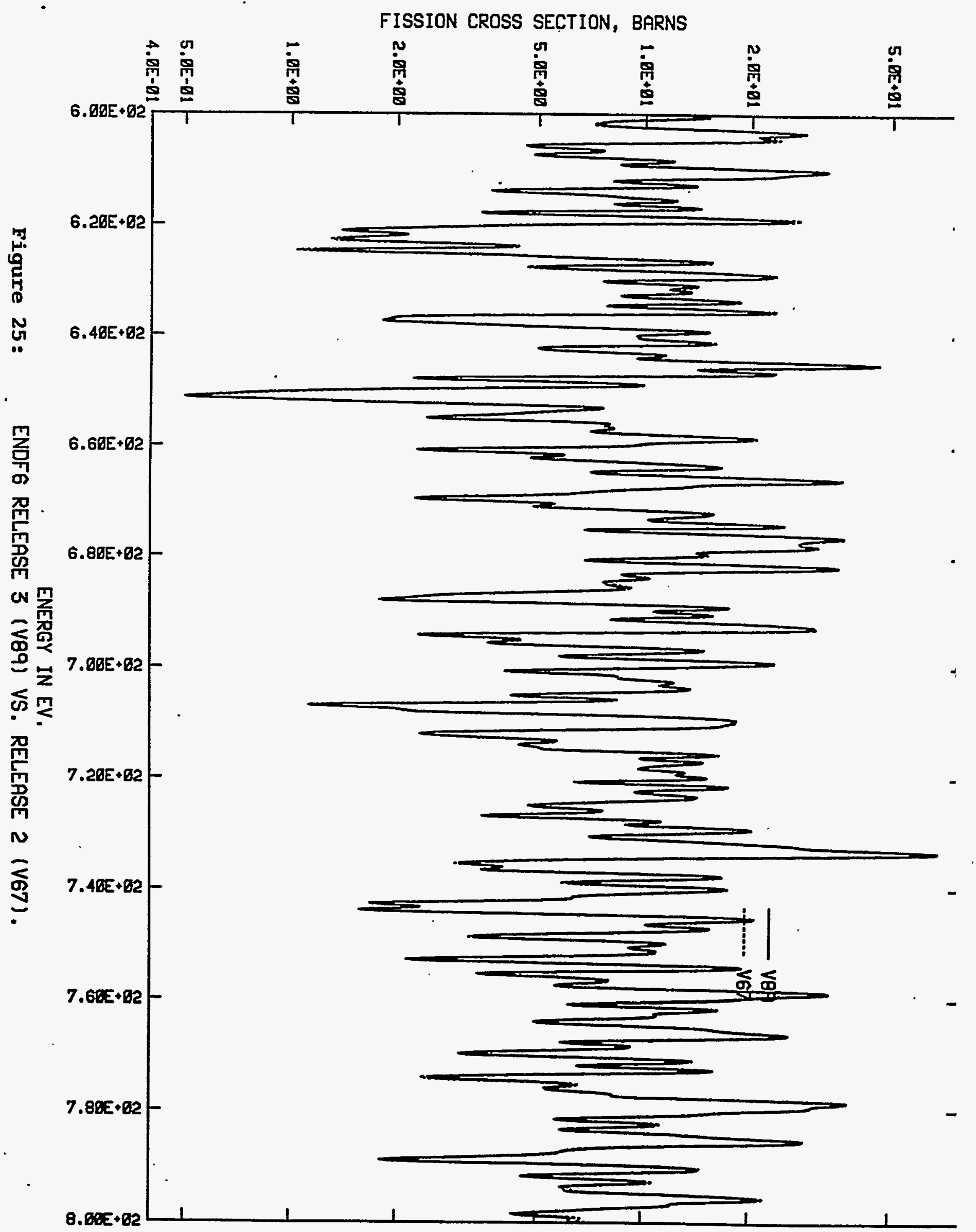




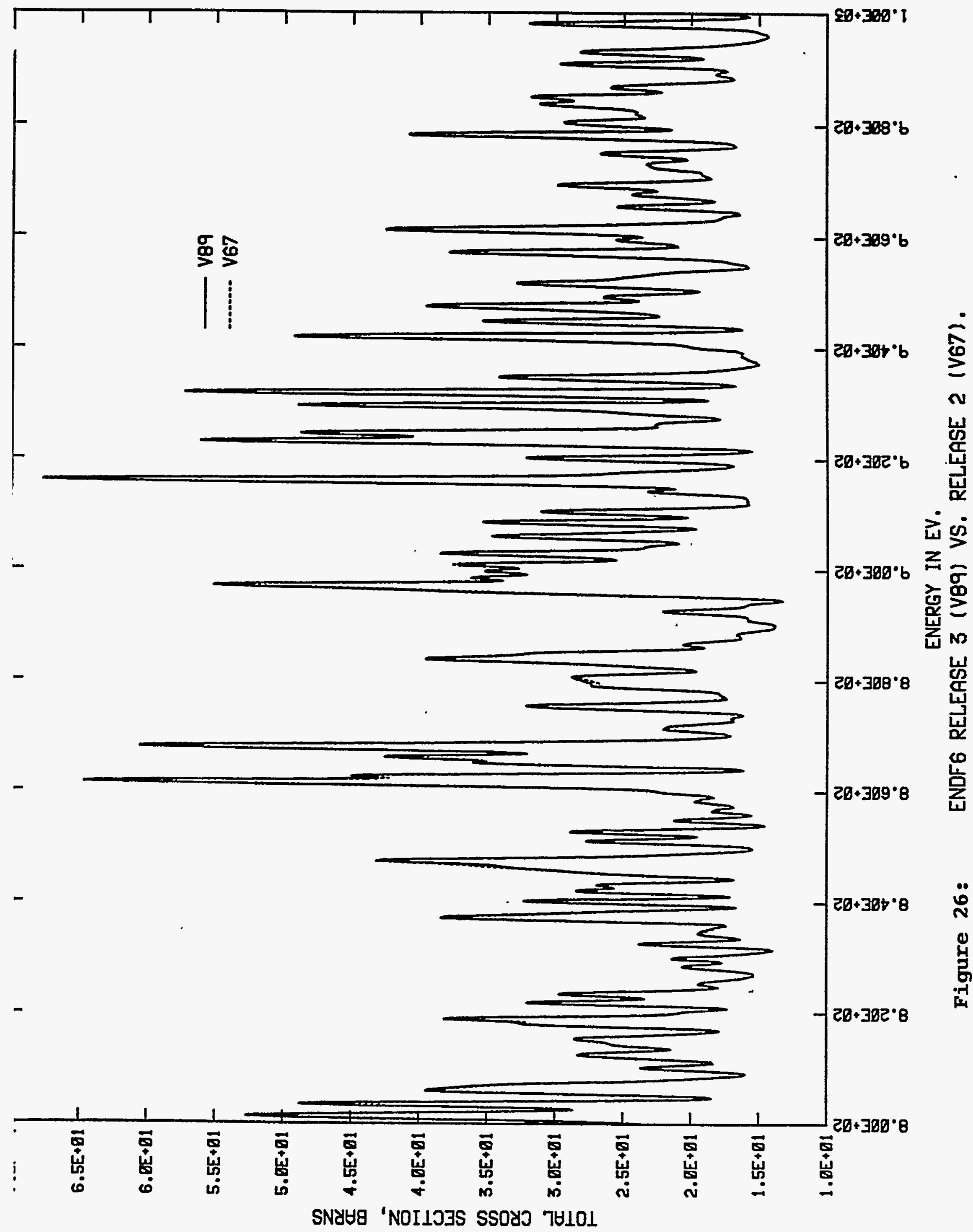

$77 / 78$

KAPL 4825 


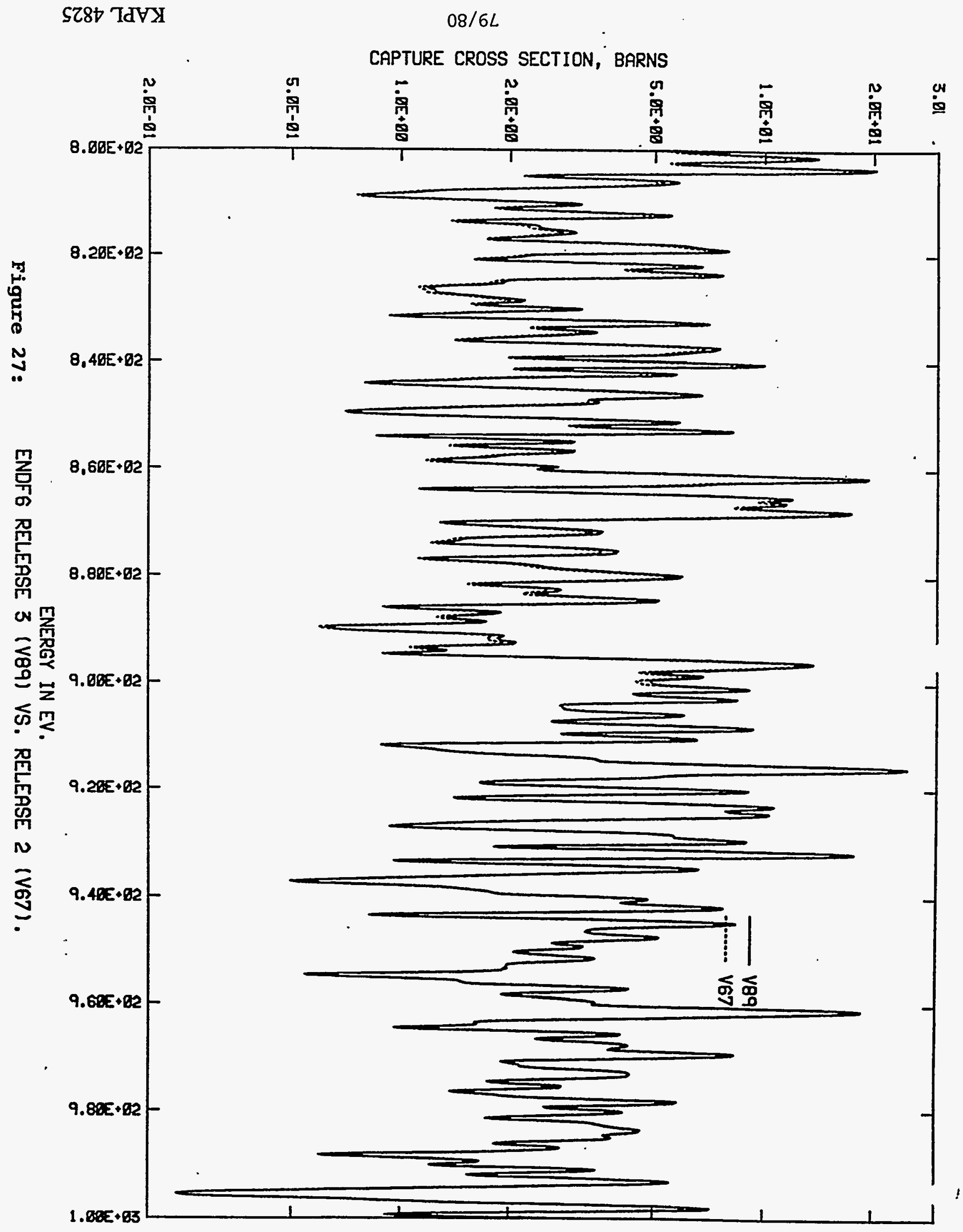




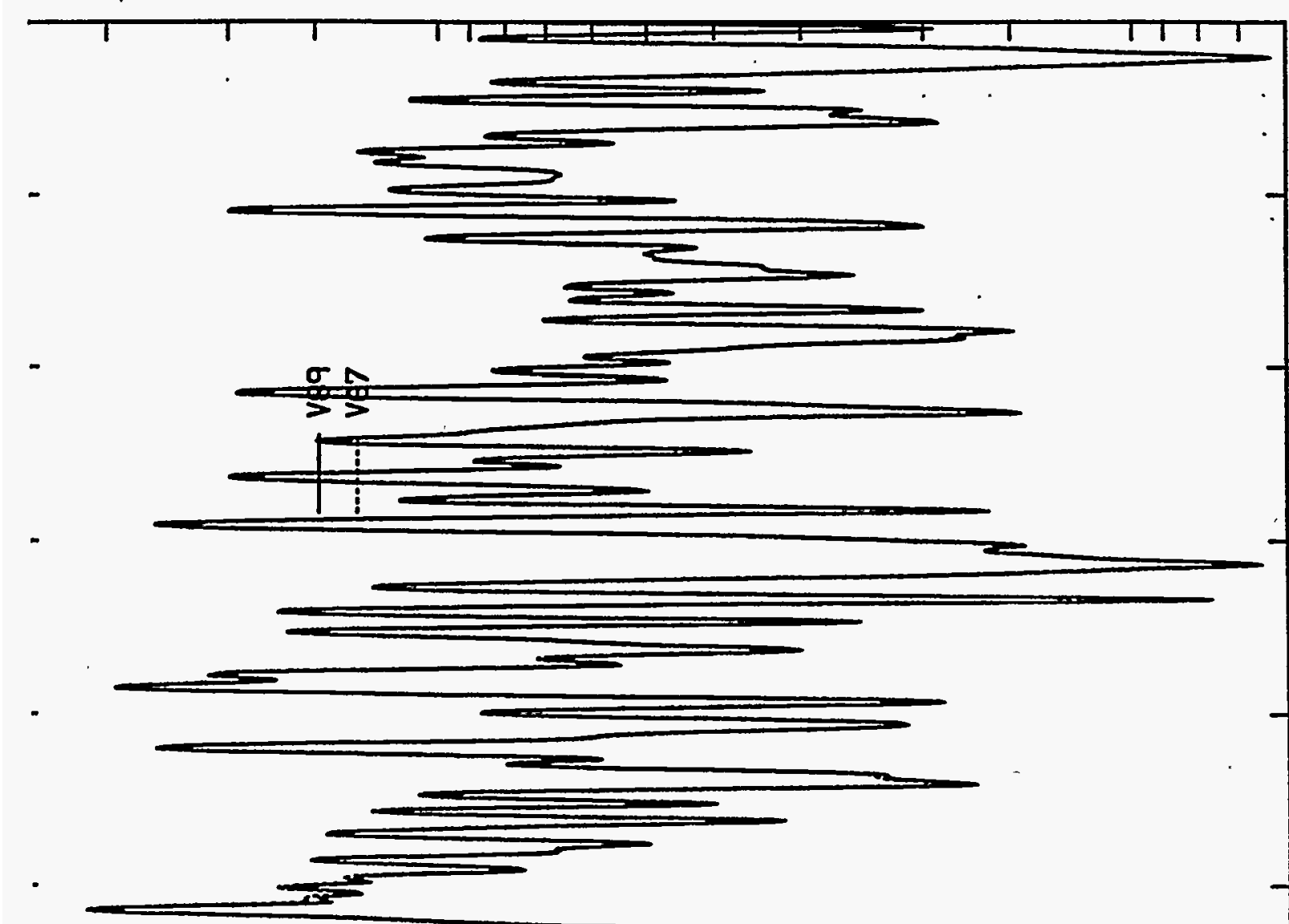

$20 \cdot 398 \cdot 1$

$28+3388^{\circ} \mathrm{b}$

$20+399^{\circ} b$

$20+302 \cdot 6$

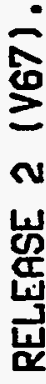

$\dot{m}$

$20+380 \cdot 6$

$z$

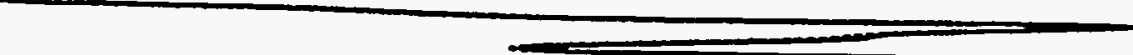

2810

$20+396 \cdot 6$
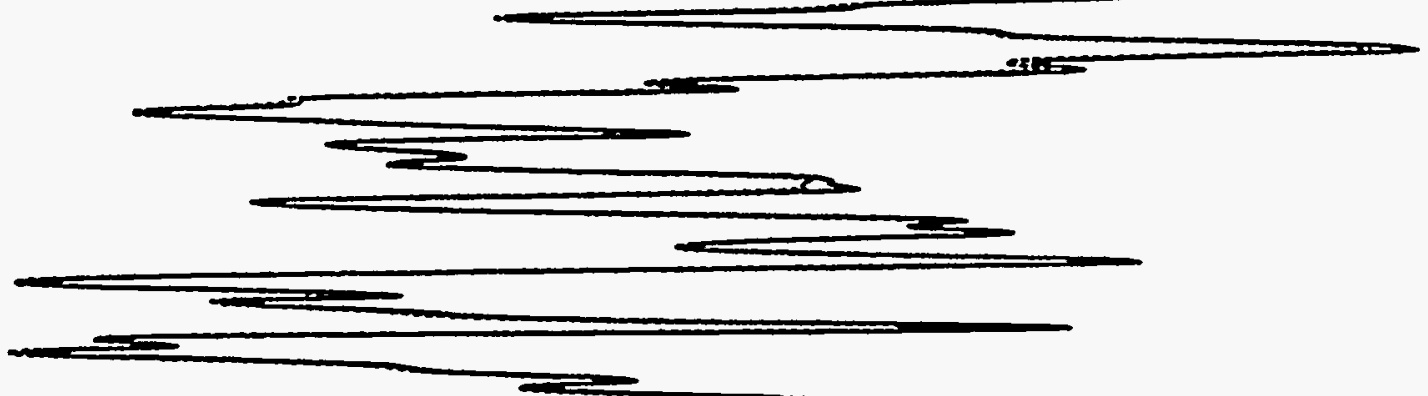

-

$28+388^{\circ} \theta$

L

ชั

2

W

$\longrightarrow$
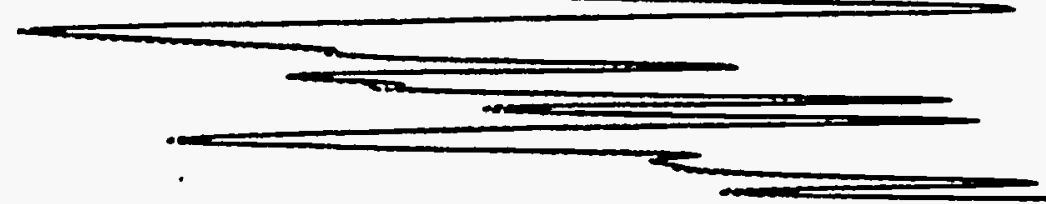

$\longrightarrow$

$\longrightarrow$

$\longrightarrow$

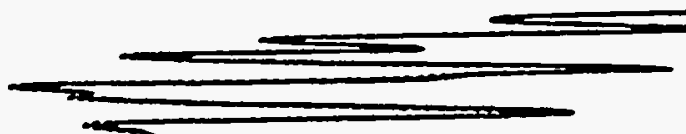

